\title{
PARÂMETROS FÍSICO-HÍDRICOS DE UM SOLO SEM COBERTURA VEGETAL E AVALIAÇÃO DO MODELO DE UMIDADE DO SOLO PARA ATIVIDADES AGRÍCOLAS (MUSAG)
}

\author{
JOSÉ VANGLESIO DE AGUIAR \\ Engenheiro Agrônomo
}

Orientador: Prof. Dr. Luiz Roberto Angelocci

Tese apresentada à Escola Superior de Agricultura "Luiz de Queiroz", da Universidade de São Paulo. para obtenção do título de Doutor em Agronomia. Area de concentração: Irrigação e Drenagem.

\footnotetext{
PIRACICABA

Estado de São Paulo - Brasil

Janeıro - 1997
} 
Aguiar, José Vanglesio de

Parâmetros fisico-hidrico de um solo sem cobertura vegetal e avaliação do modelo de umidade do solo para atividades agricolas (MUSAG) / José Vanglesio de Aguiar. - Piracicaba, 1997.

76 p. : il.

Tese (doutorado) - Escola Superior de Agricultura Luiz de Queiroz, 1997. Bibliografia.

1. Evaporação 2. Infiltração 3. Irrigação 4. Umidade do solo - Modelo I. Título

CDD 631.432 


\section{PARÂMETROS FÍSICO-HÍDRICOS DE UM SOLO SEM COBERTURA VEGETAL E AVALIAÇĀO DO MODELO DE UMIDADE DO SOLO PARA ATIVIDADES AGRÍCOLAS (MUSAG)}

JOSÉ VANGLESIO DE AGUIAR

Aprovada em: 28.02.1997

Comissão Julgadora:

Prof. Dr. Luiz Roberto Angelocci

ESALQ/USP

Prof. Dr. Marcos Vinicius Folegatti ESALQ/USP

Prof. Dr. Paulo Leonel Libardi ESALQ/USP

Prof. Dr. Luis Carlos Uchôa Saunders CCAUFC

Prof. Dr. Osny Oliveira Santos Bacchi CENAUSP

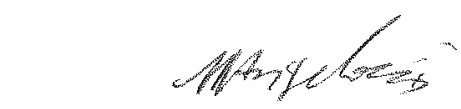

Prof. Dr. Luiz Roberto Angelocci

Orientador 
Ao meu pai, Francisco Abílio de Aguiar "in memorian", com imensa saudade, a minha mãe Vicencia Marques de Aguiar, aos meus irmãos Zewalter, Wilma, Wanderley e Waldir, OFEREÇO

Aos meus filhos, Alexandre, Aristóteles,Gustavo, Patricia e Camila,

$$
\text { DEDICO }
$$




\section{AGRADECIMENTOS}

À minha brava família que suportou a privação da minha ausência.

Ao Professor Dr. Luiz Roberto Angelocci, pela orientação valiosa recebida no desenvolvimento deste trabalho.

Aos Professores Luis Carlos Uchôa Saunders, Marcus Vinicius Folegatti, Paulo Leonel Libardi e José Antonio Frizzone pelo aconselhamento, críticas e sugestões apresentadas.

A todos os professores do Departamento de Engenharia Rural e do Departamento de Física e Meteorologia pelos ensinamentos recebidos

Aos Professores do Departamento de Engenharia Agrícola da Universidade Federall do Ceará, pela aprovação concedida para o meu afastamento.

Á FUNCEME pelo apoio financeiro recebido para a execução dos trabahos de campo e ao Dr. Antonio Ribeiro Zaranza pela presteza na resolução das exigências burocráticas.

À Coordenação de Aperfeiçoamento de Pessoal de Nivel Superior (CAPES), pela bolsa de estudo concedida durante o curso.

Ao Eng.Agro. Sérgio Horta Mattos e aos Técnicos Agrícolas Walmir Chagas da Silva e João Calixto Filho pelo apoio logístico sempre presente na execução deste trabalho. 
Aos colegas Adunias e Nonato pela vontade de colaborar sempre presente.

Ao Engr.Agro. Fernando Antonio Teixeira Mendes, grande amigo a quem devo parte dos meus conhecimentos em informática.

Ao Químico Nelson Maniasso, grande companheiro, responsável pela generosa acolhida em Piracicaba.

Ao colegas de curso Marcelo Targa, Vital, Tangerino e Altair pela amizade e convívio durante o curso.

Ao jovem Francisco José Ferreira Gama pela dedicação e responsabilidade demonstrados no apoio aos trabalhos de campo.

A todos funcionários da Fazenda Experimental do Vale do Curu, do Departamento de Engenharia Agrícola da UFC e do Departamento de Engenharia Rural da ESALQ, por todas ajudas dispensadas para a concretização dessa pesquisa. 
S U MÁ R IO

Página

LISTA DE FIGURAS

LISTA DE QUADROS $\mathrm{x}$

RESUMO

$\mathbf{X i}$

SUMMARY

$X v$

1. INTRODUÇÃO

2. REVISÃO DE LITERATURA 4

2.1. Infiltração da água no solo . . . . . . . . . . . . 7

2.2. Evaporação da água do solo . . . . . . . . . . . . . . . 18

3. MATERIAL E MÉTODOS . . . . . . . . . . . . . . . 23

3.1. Descrição do modelo . . . . . . . . . . . . . . . . . 23

3.2. Caracterização da área da pesquisa . . . . . . . . . . . . 26

3.3. Determinação da umidade do solo e dos gradientes de potencial $\ldots \ldots \ldots \ldots \ldots \ldots \ldots$

3.4. Determinação dos parâmetros de infiltração, percolação e evaporação

3.5. Procedimentos para avaliação do MUSAG 36 


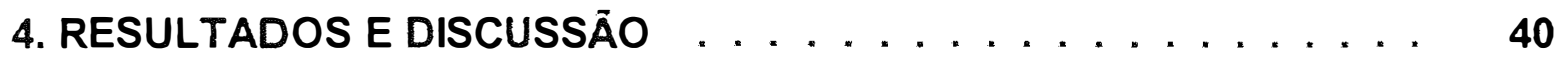

4.1. Armazenamento da água no solo ............. 40

4.2. Função de infiltração . . . . . . . . . . . . . . . . . 46

4.3. Função de percolação. . . . . . . . . . . . . . . . . . 52

4.4. Função de evaporação . . . . . . . . . . . . . . . . . 59

4.5. Avaliação do modelo ajustado . . . . . . . . . . . . . . 62

5. CONCLUSÕES . . . . . . . . . . . . . . . . . 68

REFERÊNCIAS BIBLIOGRÁFICAS . . . . . . . . . . . . . . 70 


\section{LISTA DE FIGURAS}

Página

1 Tipos de solos do Estado do Ceará . . . . . . . . . . . . . . 28

2 Distribuição de tubos de acesso na área experimental.

Pentecoste-Ce,1995 . . . . . . . . . . . . . . 30

3 Conteúdo de água e precipitação pluvial no período de

11/02 a 30/06/95. Pentecoste-CE, $1995 \ldots$. . . . . . . . . . . . 45

4 Curva de velocidade de infiltração e da infiltração acumulada da água no solo (Tubo 2), Pentecoste-Ce . . . . . . . . . . 50

5 Redistribuição da água no solo (Tubo 1), Pentecoste-Ce . . . . . . 53

6 Redistribuição da água no solo (Tubo 2), Pentecoste-Ce . . . . . . 53

7 Redistribuição da água no solo (Tubo 3), Pentecoste-Ce . . . . . . . 54

8 Redistribuição da água no solo (Tubo 5), Pentecoste-Ce . . . . . . . 54

9 Redistribuição da água no solo (Tubo 6), Pentecoste-Ce . . . . . . 55

10 Redistribuição da água no solo (Tubo 8), Pentecoste-Ce . . . . . . 55

11 Redistribuição da água no solo (Tubo 9), Pentecoste-Ce . . . . . . 56

12 Condutividade hidráulica como função da umidade . . . . . . . . 58 
13 Armazenamentos estimado e observado no período de 11/02 a 30/06/95, Pentecoste-Ce . . . . . . . . . . . . . 62

14 Correlação entre as médias mensais dos armazenamentos estimados e observados no período de 11/02 a 30/06/95, Pentecoste-Ce . . . . . . . . 
1 Medida da umidade do solo $\left(\mathrm{cm}^{3} \cdot \mathrm{cm}^{-3}\right)$ e do coeficiente de variação da sonda de neutrons. Pentecoste-Ce.1995 . . . . . . .

2 Armazenamento cumulativo $(\mathrm{mm})$ d'água no solo - Período 11/02 a 30/06/95. Pentecoste-Ce . . . . . . . . . . . . . . .

3 Variâncias do armazenamento devido à umidade e ao método de integração das medidas da sonda - Pentecoste-Ce, $1995 \ldots 43$

4 Características físicas do solo - Pentecoste-Ce . . . . . . . . 46

5 Gradientes de potencial hidráulico-Pentecoste-Ce . . . . . . . . 58

6 Resumo dos parâmetros de avaliação estatística do MUSAG no período de $11 / 02$ a 31/06/95 - Pentecoste-Ce . . . . . . . . . . 64

7 Resumo dos parâmetros de avaliação estatística do MUSAG no período de $11 / 02$ a 08/04/95 - Pentecoste-Ce . . . . . . . . . . 67

8 Resumo dos parâmetros de avaliação estatística do MUSAG no período de 09/04 a 30/06/95 - Pentecoste-Ce . . . . . . . . . . 


\title{
PARÂMETROS FÍSICO-HÍDRICOS DE UM SOLO SEM COBERTURA
}

\section{VEGETAL E AVALIAÇÃO DO MODELO DE UMIDADE DO SOLO}

PARA ATIVIDADES AGRÍCOLAS (MUSAG)

\author{
Autor: José Vanglesio de Aguiar
}

Orientador: Prof. Dr. Luiz Roberto Angelocci

\section{RESUMO}

O presente trabalho foi conduzido numa região semi-árida em solo bruno não cálcico com horizonte superficial $\left(A_{p}\right)$ arenoso e subsuperficial $\left(B_{t}\right)$ argiloso. A área experimental de dimensões de $80 \mathrm{~m} \times 120 \mathrm{~m}$ localiza-se na Fazenda Experimental do Vale do Curu da Universidade Federal do Ceará. O experimento se desenvolveu no período de 11/02/95 a 20/12/95, mantendo o solo sem vegetação e teve como objetivos testar, o Modelo de Umidade do Solo para Atividades Agrícolas 
(MUSAG), e determinar os parâmetros associados às funções que compõem o modelo (infiltração, percolação e evaporação).

O teste consistiu em medir a umidade do solo, às profundidades de 20 , $40,60,80$ e $100 \mathrm{~cm}$, com uma sonda de neutrons, e comparar essas medidas com a umidade do solo estimada pelo modelo parametrizado,

$\mathrm{Na}$ determinação das constantes de infiltração realizaram-se testes visando aferir a velocidade de infiltração da água no solo, em função da umidade e do tempo, para obtenção da capacidade máxima de infiltração e da velocidade de infiltração básica.

Para obtenção dos parâmetros da equação de percolação, determinouse a relação entre a condutividade hidráulica e a umidade do solo pelo método de Libardi (1980). Foram medidos também os potenciais de água no solo através de 8 baterias de tensiômetros instalados a 10,30,50,70, 90 e $110 \mathrm{~cm}$, calculando-se a drenagem interna e correlacionando-se com a umidade do solo.

A evaporação do solo foi estimada através de um submodelo, cujas variáveis de entrada são a evapotranspiração potencial, a umidade atual e a umidade de saturação do solo. A evapotranspiração potencial foi estimada pelo método do Tanque Classe A. Para determinação dos parâmetros de ajuste (k e $\beta$ ) do submodelo, a evaporação foi determinada através do balanço hídrico no campo, em dias sem chuva.

Todos os parâmetros do modelo, foram determinados por regressão linear. 
No solo estudado, identificou-se uma grande taxa de infiltração inicial pelo solo seco (420 a $810 \mathrm{~mm} / \mathrm{h}$ ), e uma baixa velocidade de infiltração básica (3 a $18 \mathrm{~mm} / \mathrm{h})$.

A drenagem interna mostrou-se desprezível a partir de $40 \mathrm{~cm}$ de profundidade quando a umidade do solo se reduz a menos de $85 \%$ da umidade de saturação e a evaporação potencial média alcançou 3,67 mm/dia; a evaporação acumulada apresentou valores mínimos nos meses de abril e maio, coincidentes com a época de menor deficit de saturação do ar e maiores precipitações pluviais.

Para a avaliação estatística do modelo ajustado, utilizaram-se o desvio padrão, o desvio relativo, o erro padrão, o coeficiente de correlação e o teste "t". A verificação da normalidade da distribuição dos desvios entre os valores de umidade observados e estimados, foi feita pelo coeficiente de assimetria e curtose, e pela reta de Henry.

Para todas as profundidades, à exceção de $40 \mathrm{~cm}$, os valores calculados de " $t$ " estiveram sempre abaixo do valor tabulado, para um nivel de significância de 1,0\%, levando-se a aceitar que a diferença entre as médias das armazenagens observadas e estimadas é nula; conclui-se que o modelo pode ser utilizado para estimar a umidade do solo em condições de solo e clima semelhante aos da região onde foi desenvolvida a pesquisa. 


\section{PHISICAL AND HYDRIC PARAMETERS OF A BARE SOIL AND THE EVALUATION OF THE SOIL MOISTURE MODEL FOR AGRICULTURAL ACTIVITIES (MUSAG)}

Author: José Vanglesio de Aguiar Adviser: Prof. Dr. Luiz Roberto Angelocci

SUMMARY

This work was carried out at the Experimental Farm Station of Universidade Federal do Ceará, Curu River Valley, Ceará, State Brazil, from February $11^{\text {th }}, 1995$ to Jun $30^{\text {th }}, 1996$, to test, at field conditions, the so called "Soil Moisture Model for Agricultural Activities (MUSAG) determining the parameters associated to the model functions (infiltration, percolation and evaporation).

The tests were done in a area of $80 \mathrm{~m} \times 120 \mathrm{~m}$ of bare soil, classified as Brunei non calcic, with a sand surface sandy horizon (Ap) and a clay subsurface (Bt) 
horizon, and the soil moisture measurements at 20,40,60, 80 e $100 \mathrm{~cm}$, were done with a neutron probe.

The measurements of soil water storage were compared with that predicted by the model. The parameters of infiltration equation were determined as a function of soil moisture and time; the maximum infiltration and basic infiltration were also estimated.

The parameters of percolation equation were obtained using the Darcy's equation. For this, the relationship between the non-saturated hydraulic conductivity versus soil moisture, was obtained by the Libardi's method and soil water potential was determined using 8 batteries of tensiometers installed at 10,30 , $50,70,90$ e $110 \mathrm{~cm}$ depth.

Soil evapotranspiration was estimated by a submodel which the variables are potential evapotranspiration, actual and saturated soil moisture. In order to determine the submodel parameters, actual evaporation was calculated from the soil water balance "in situ" in days without rainfall. For this calibration and for the calculus in the MUSAG, potential evapotranspiration was estimated by the Class $A$ evaporation pan method.

Linear regression by the least square method was used to obtain all the model parameters.

Water intake was very high for dry soil conditions $(420 \mathrm{~mm} / \mathrm{h}$ a 810 $\mathrm{mm} / \mathrm{h}$ ) but the stabilized infiltration rate was low (3 to $18 \mathrm{~mm} / \mathrm{h}$ ). 
Deep percolation was negligible below $40 \mathrm{~cm}$, when soil moisture showed values less than $85 \%$ at the saturation water content and the mean potential evapotranspiration reached $3,67 \mathrm{~mm} /$ day; monthly actual evaporation reached minimum values during April and May, coinciding with the lowest saturation air deficit and highest rainfall.

Statistical analysis comprised the determination of standard deviation, standard error, correlation coefficients, and the " $t$ "test. The normality of the distribution of the deviation between the predict and the measured soil water content, was verified by the asymmetry and kurtosis coeficients and by Henry's line.

For all depths, except $40 \mathrm{~cm}$, the 't' values were always below the tabulated values (at the $\alpha=0,01$ significance level); there were no difference between calculated and observed values for mean water storage.

Thus, the MUSAG may be used to estimate soil water content, in soils and climate with conditions similar to the experimetal site. The fact that the model was not adequate for 30 to $50 \mathrm{~cm}$ layer, can be due to a great textural change in the soil, causing water flux reduction, characterizing a limiting layer. 


\section{INTRODUÇÃO}

O conhecimento do regime de umidade do solo reveste-se de grande importância no fornecimento de informações destinadas a resolver problemas como manejo de irrigação, escolha da época de plantio, determinação do consumo de água pelas plantas, estudos dos processos de transferência no sistema solo-plantaatmosfera, planejamento dos sistemas de drenagem, etc. Em áreas onde a disponibilidade de água no solo torna-se problemática em termos quantitativos, o monitoramento da umidade do solo adquire maior significância.

Na região do semi-árido nordestino, os deficits hídricos ocorrem com bastante frequência, colocando em risco a produção das culturas anuais, em grande parte em regime de sequeiro, sendo fundamental a adequação da época de plantio ao nível de umidade favorável à germinação das sementes.

No Estado do Ceará, praticamente em todas as regiões, o balanço hídrico evidencia um excesso de água no solo, no máximo em 3 (três) meses do ano (março, abril e maio), com exceção da serra da Ibiapaba. Computando o ano de forma global, todas as regiões apresentam déficits, sendo que em um grande número de municípios não se verifica excesso em nenhum mês do ano. Excetuando as áreas litorâneas, das terras e a região do Cariri, as precipitações pluviais médias 
anuais, não alcançam 800 mm, enquanto a evapotranspiração potencial varia de 1 500 a $1800 \mathrm{~mm}$ anuais.

Nas condições semi-áridas do Ceará, além das baixas intensidades e da má distribuição das chuvas, é praticamente impossível a medida da umidade do solo na grande maioria dos locais por ocasião do plantio, elevando consideravelmente a probabilidade de fracasso das colheitas, além da elevação dos custos com replantio.

A modelagem ocupa, atualmente, uma posição importante no mundo científico, tendo sido desenvolvido, nos últimos 20 anos, um grande número de modelos, cuja sofisticação depende dos objetivos desejados e, principalmente, da disponibilidade de dados (SILVA \& DE JONG, 1986).

A confiabilidade dos resultados dos modelos de transporte de água existentes, ainda é um ponto de preocupação, devido a dificuldade de se adequar um modelo para simular os fluxos de água no sistema solo-planta-atmosfera (CLEMENTE et al. 1994). Para simular esses fluxos, os modelos baseados em princípios físicos e os semi-empíricos têm-se mostrado mais apropriados; os modelos físicos requerem um mínimo de calibração local, produzem resultados mais precisos e demandam um grande número de informações; os semi-empíricos englobam processos físico-biológicos numa abordagem simplificada, exigem maior esfôrço de calibração local, utilizam parâmetros de fácil obtenção, mas produzem resultados com maior margem de erros (FARIA et al. 1992).

MOLINA \& ANDRADE (1991) desenvolveram um modelo para estimar a umidade do solo em 160 locais do Estado do Ceará, utilizando a rede estadual de postos pluviométricos da Fundação Cearense de Meteorologia e Recursos Hídricos 
(FUNCEME), denominado Modelo de Umidade do Solo para Atividades Agrícolas (MUSAG), cuja utilização tem sido obrigatória no planejamento e execução do programa de distribuição de sementes selecionadas do Governo do Estado do Ceará, denominado "Programa Hora de Plantar". Os parâmetros de entrada do modelo foram obtidos a partir de levantamentos exploratórios, agrupamento de tipos de solos e dados da relação chuva/vazão das bacias hidrográficas, revelando a adoção de um caráter bem generalizado, compreensivel face a pequena disponibilidade de dados necessários e suficientes para o processo de validação.

A forma mais adequada para se avaliar um modelo de umidade do solo é testá-lo em campo, comparando os resultados obtidos diretamente, com os resultados estimados pelo modelo.

O presente trabalho, tem como objetivos o ajuste das funções de infiltração, percolação e evaporação exigido pelo MUSAG, para um solo representativo de uma região fisiograficamente definida do Estado do Ceará e testar o modelo, no campo, através da comparação entre os dados estimados a partir dele com os valores medidos de armazenagem de água no solo. 


\section{REVISÃO DE LITERATURA}

O movimento da água em meios porosos começou a ser estudado do ponto de vista quantitativo no ano de 1856 por Henri Darcy, que postulou as relações básicas que descrevem o fluxo da água em meios saturados; Buckingham em 1907 ofereceu uma contribuição valiosa à compreensão das forças de retenção da água pelo solo; GARDNER (1920) desenvolveu os conceitos de energia da água e sua relação com a umidade do solo; onze anos depois, RICHARDS (1931) apresentou as equações básicas que descrevem o fluxo da água em um meio não saturado; a formulação desses conceitos serviu de base para a compreensão e descrição do movimento da água no solo, a partir dos anos 50.

O mundo vem enfrentando nos últimos vinte anos problemas complexos relacionados à disponibilidade e distribuição de água no planeta, à necessidade de conservação da produtividade dos solos, à manutenção dos recursos naturais tanto do ponto de vista qualitativo, como quantitativo e ao controle da poluição ambiental.

Em face dessa exigência crescente e com o avanço da ciência computacional, a técnica da modelagem apresentou nas duas últimas décadas um grande desenvolvimento, com a sua utilização cada vez mais presente na busca de soluções para os problemas hidrológicos. 
Segundo GURALNK (1986), modelo é uma "descrição hipotética generalizada, muitas vezes baseada em uma analogia, usada para análise de alguma coisa".

HAAN (1988) define um modelo como um "conjunto de leis físicas e observações empíricas escritas em termos matemáticos e combinadas de forma a produzir resultados baseados numa série de condições conhecidas ou assumidas".

Para os propósitos deste estudo, modelo é uma representação matemática de um fenômeno hidrológico, baseado em leis físicas e observações empíricas, com o objetivo de produzir um resultado a partir de dados medidos ou estimados.

A modelagem pode se constituir num importante instrumento na agricultura atual. Simulações computacionais podem ser desenvolvidas, por exemplo, para identificar como os diferentes manejos da água e do solo, sob diferentes climas, podem afetar a erodibilidade ou a salinização dos solos, a profundidade do lençol freático ou a lixiviação dos nutrientes. Atualmente os modelos veem sendo utilizados para preencher lacunas ainda existentes no conhecimento e interpretação dos fenômenos hidrológicos, principalmente quando se baseia em princípios e leis gerais que regem os fenômenos físicos.

Apesar da técnica de modelagem constituir um importante instrumento na solução dos problemas hidrológicos, deve-se ter muita cautela na adoção de um determinado modelo, considerando o seu grau de aplicabilidade.

A incerteza no grau de confiabilidade de um modelo, está associada à variabilidade inerente ao fenômeno em si, ao modelo propriamente dito e à estimação dos parâmetros. No caso do presente estudo, a e do fenômeno natural 
refere-se aos fatores meteorológicos como chuva, temperatura, radiação solar, etc, e das características físico-hídricas do solo.

A incerteza do modelo em si, está associada à necessidade de simplificações decorrentes da impossibilidade de um modelo reproduzir completa e fielmente, o fenômeno físico. Nos modelos de infiltração, por exemplo, o fluxo da água no solo é considerado somente no estado líquido, embora possa ocorrer também no estado gasoso. Segundo HAAN (1988), a incerteza dos parâmetros reflete na obtenção de modelos incompletos, dada a utilização de técnicas de estimação inadequadas. A coleta de dados que vai originar um determinado modelo, muitas vezes é executada por pessoas diferentes e às vezes pela mesma pessoa, mas utilizando conjuntos diferentes; esses procedimentos levam a um grau de incerteza nos parâmetros.

Visualizando o ciclo hidrológico como a célula base dos estudos do movimento da água no solo e na atmosfera, houve por parte dos pesquisadores de todo o mundo, esforços consideráveis para o desenvolvimento de modelos capazes de estimar as precipitações pluviométricas, o fluxo da água no solo, a magnitude dos processos de escoamento superficial e as perdas por evaporação do solo e por transpiração das plantas.

A despeito desses esforços, algumas lacunas ainda existem na modelagem hidrológica. Uma delas é a análise de sensibilidade, considerando que todos os modelos possuem uma margem de incerteza, como componente inevitável dos sistemas da natureza.

É impossivel existir um modelo que faça estimativas corretas e repetidamente em todas as circunstâncias. Daí a necessidade da análise de sensibilidade para 
averiguar o comportamento do modelo face às variações dos parâmetros que o influencia.

Deve-se reconhecer que a sofisticação matemática não substitui a compreensão dos processos básicos. Muitas vezes os propósitos do desenvolvimento de um modelo têm sido negligenciados pelo fascínio das técnicas matemáticas, estatísticas e computacionais. Estas são tão somente um meio e não um fim em si mesmo. O reconhecimento honesto deste fato permitirá um melhor conhecimento da física, da química e da biologia do solo e ajudará na elaboração de modelos mais reais, mais abrangentes e mais representativos dos fenômenos estudados (HAAN, 1988).

Para qualquer enfoque que seja dado a um estudo de modelagem, deve-se ter sempre em mente a obrigatoriedade da realização de testes para a sua validação, em diferentes circunstâncias, principalmente aqueles que se enquadram na classificação de semi-empíricos.

\subsection{Infiltração da água no solo}

A quantidade de água que entra na interface solo-atmosfera por unidade, de tempo e de área, tem recebido diferentes denominações por parte dos pesquisadores, sendo as mais consagradas, velocidade de infiltração, taxa de infiltração e capacidade de infiltração do solo; neste trabalho, adotaremos indistintamente qualquer um dos termos, com a simbologia (i) (REICHARDT, 1993; HAAN; 1988; LIBARDI, 1996). 
Quando a precipitação pluvialtem uma intensidade $\mathbf{P}$ menor que a capacidade de infiltração do solo, toda a água penetra no solo e $\mathbf{i}=\mathbf{P}$, sendo $\mathbf{i}$ limitada por $\mathbf{P}$, muito mais que pelas características do solo; quando $\mathbf{P}$ é maior que a capacidade de infiltração do solo, i será limitada pelas características do perfil, e haverá água disponivel para armazenagem sobre o solo ou para o escoamento superficial (SKAGGS \& KHALEEL, 1982).

A capacidade de infiltração diminui à medida que o solo vai se umedecendo, e para um tempo muito longo, ela tende para um valor constante, conhecida como velocidade de infiltração básica (VIB).

Considerando um período de tempo $\mathbf{t}$, a infiltração acumulada I pode ser expressa pela integral:

$$
I(t)=\int i(t) d t
$$

O movimento da água no solo não saturado tem sido descrito desde o início do século pelo modelo de Darcy-Buckingham (REICHARDT, 1993; LIBARDI, 1995), que pode ser expresso assim:

$$
q_{s}=-K(\Theta) \cdot d H / d s
$$

onde: $q_{s}$ é o volume de água que penetra no solo na direção s, por unidade de área e de tempo; $\mathbf{K}$ é condutividade hidráulica do solo; $\mathbf{d H / d s}$ é o gradiente de potencial total da água no solo; e $\Theta$ é o conteúdo de água do solo.

Na prática, $\mathbf{H}$ pode ser considerado como a soma do potencial mátrico $\mathbf{h}$ com o potencial gravitacional $\mathbf{z}$, sendo que se $\mathbf{h}>0$ o solo está saturado e $\Theta$ é considerado constante; se $\mathbf{h}<0$, o solo é não saturado e o potencial mátrico será função da umidade do solo. 
A quantificiação do movimento da água no solo é bastante complexo devido a vários problemas envolvidos na sua medida, como por exemplo a determinação da condutividade hidráulica. REICHARDT et alii(1993), trabalhando com 25 parcelas de $5 \mathrm{~m} \times 5 \mathrm{~m}$ em perfil de terra roxa estruturada no município de Piracicaba,SP, identificou variação de $200 \%$ para $K(\Theta)$, quando $\Theta$ variou apenas de $2 \%$.

Outra dificuldade encontrada está relacionada ao fenômeno da histerese, ou seja, para um mesmo valor de $\mathbf{h}$, da curva de retenção da água no solo, pode corresponder valores diferentes de $\Theta$, conforme o solo esteja em processo de "secamento"ou de "molhamento". Portanto, h não é uma função única de $\Theta$.

As propriedades do solo têm uma influência marcante sobre a velocidade de infiltração; durante os estágios iniciais, a estrutura do solo ou a distribuição dos tamanhos de poros, tem uma importância considerável. Nas condições de saturação e principalmente para profundidades crescentes, o gradiente hidráulico aproxima-se da unidade e a condutividade hidráulica passa a controlar o fluxo.

Considerando que a água se move no solo através do espaço poroso, uma variação na textura ou na estrutura deve provocar uma variação na característica do movimento da água.

EAGLEMAN \& JAMISON (1962) estudando o movimento da água em coluna de solo estratificado, observaram que o gradiente hidráulico no plano de contato entre um solo siltoso acima de um solo arenoso, foi pequeno comparado com o gradiente desenvolvido quando o movimento tinha o sentido inverso. Quando o movimento da água foi de camadas com poros de grande diâmetro para camadas com poros de pequeno diâmetro, não foram constatadas restrições, quando os 
volumes de ambos eram aproximadamente iguais e a diferença de tamanho não era muito grande.

HELAIA (1993) desenvolveu um estudo de campo para examinar as relações entre a velocidade de infiltração nas condições de equilíbrio dinâmico e algumas propriedades texturais e estruturais de três tipos de solo. A porosidade efetiva, definida como a porosidade total menos o conteúdo de água a tensão de $1 / 3 \mathrm{~atm}$, mostrou forte correlação com a taxa de infiltração para os três tipos de solo; considerando outras propriedades do solo (porosidade e densidade) no modelo, análises de regressão múltipla não revelaram melhoria no valor do coeficiente de determinação $r^{2}$.

Assume-se, normalmente, que o movimento da água no solo, ocorre com o ar se movendo-se através do perfil, com resistência desprezível e pressão constante, dada à sua baixa viscosidade em relação à água e admitindo-se que o ar escapa livremente através dos poros conectados com a superfície do solo. Entretanto, a ocorrência do aprisionamento do ar devido à infiltração é um fato já há muito confirmado, causando um aumento na pressão no avanço da frente de molhamento, deixando os poros com ar aprisionado, indisponíveis para o movimento da água, afetando o valor da condutividade hidráulica (SKAGGS \& KHALEEL,1982).

Tendo a maioria dos solos características heterogêneas, os valores de $K$ podem ser extremamente divergentes para um mesmo valor de $\Theta$, dada a variação de $\gamma$ na equação:

$$
K(\Theta)=K_{0} \cdot \exp \left[\gamma\left(\Theta-\Theta_{0}\right)\right]
$$


onde: $K_{0}$ é condutividade hidráulica do solo nas condições de saturação; $\Theta_{0}$ é o conteudo de água próximo à saturação; e $\gamma$ é uma constante dependente das características do solo.

No trabalho de REICHARDT et alli (1993), quando $\Theta-\Theta_{0}=-0,05$ a equação (03) foi aplicada a uma parcela com o maior valor de $\gamma$ e aplicada a uma parcela com o menor valor de $\gamma$; nessas condições, obtiveram-se valores de $K(\Theta)$ iguais a 0,223 e 4,134 mm/dia, respectivamente, equivalente a uma variação de $1.850 \%$.

Outro fator que influencia a capacidade de infiltração do solo é o seu conteúdo inicial de água. Para um mesmo tipo de solo, quanto mais seco estiver, maior será a velocidade de infiltração, devido a maior porosidade efetiva e ao maior número de poros disponíveis para infiltração da água.Esta dependência vai diminuindo com o decorrer do tempo até atingir a velocidade de infiltração básica, que é a mesma independentemente do conteúdo inicial da água, mas influenciando o avanço da frente de molhamento (PHILIP, 1957).

MEIN \& LARSON (1973) propuseram um modelo em dois estágios em função das propriedades do solo, conteúdo inicial de água e intensidade de precipitação; o primeiro estágio é um período em que não há escoamento superficial e estima-se a lâmina infiltrada antes de começar o escoamento superficial e no segundo estágio, estima-se a lâmina infiltrada após iniciar o escoamento, havendo portanto, um excesso de infiltração.

Apesar das enormes dificuldades para se caracterizar de forma precisa o processo de infiltração, muitos esforços tem sido desenvolvidos na formulação de 
modelos para explicar o processo, do ponto de vista da variação da umidade do solo no tempo e no espaço, perdas por percolação profunda, escoamento superficial, etc.

Uma das equações mais simples, para o processo de infiltração, foi proposta por KOSTIAKOV (1932); embora seus parâmetros não tenham significado físico, é de grande aceitação dada à sua facilidade de ajuste à maioria dos dados:

$$
i=i_{0} \cdot t^{-b}
$$

onde: $\mathbf{t}$ é o tempo decorrido após o início da infiltração; $i_{0}$ é a velocidade de infiltração para $\mathbf{t}=\mathbf{0}$ e $\mathbf{b}$ é uma constante que depende das características e das condições iniciais de umidade do solo, variando de 0 a 1.

O cálculo da infiltração acumulada é dado pela integral de (04), no intervalo de 0 a t, resultando:

$$
1=I_{0} \cdot t^{1-b} / 1-b
$$

Experiências têm revelado que o fator exponencial $\mathbf{b}$ tem variado de 0.24 a 0.70 Para solos inicialmente secos e de textura fina, b pode variar entre 0.4 e 0.6 , enquanto para solos arenosos e mais úmidos, onde o potencial gravitacional passa a predominar, o valor de $\mathbf{b}$ cresce aproximando-se de 1,0 (PAPADAKIS \& PREUL, 1973).

A equação de Kostiakov não se adapta bem para tempos muito longos, para os quais prevê $\mathbf{i}$ tendendo para zero, quando na prática, à medida que $\mathbf{t}$ aumenta, $\mathbf{i}$ diminui, tendendo para um valor constante $\mathbf{i}_{\mathbf{f}}$, sendo que o valor de $\mathbf{b}$ depende do intervalo de tempo utilizado no ajuste dos dados. Por isso, alguns pesquisadores tem utilizado a equação de Kostiakov adicionando o termo C.t ao segundo membro da equação original. 
À equação de Kostiakov modificada pode-se associar uma interpretação física aos parâmetros, como sendo, $\mathbf{i}_{\text {o }}$ representando a sortividade do solo, $\mathbf{b}=0,5$ e $C$ correspondendo à condutividade hidráulica do solo saturado. Uma abordagem deste tipo foi feita por SMITH \& HERBBERT (1983).

Embora a equação de Kostiakov modificada torne-se adequada para valores extremos de $\mathbf{t}$, erros de 30 a $40 \%$ para valores intermediários, é um fato constatado.

Philip apresentou uma solução tabular para a taxa de infiltração adimensional como função do tempo, tambem adimensional, da forma:

$$
\begin{aligned}
& i^{*}=i / K_{0} \\
& t^{*}=\left(4 K_{0}{ }^{2} / \pi S\right) t
\end{aligned}
$$

onde $\mathbf{S}$ é a sortividade, um parâmetro referente à capacidade do solo de absorver água, dependendo do nível atual de umidade.

Para eventos de infiltração de tempos longos, sempre que possivel, deve ser preferida a equação de Kostiakov modificada em lugar da equação original. Particularmente, para solos de textura fina, a condutividade hidráulica pode ser tão pequena que a inclusão do segundo termo (C.t) pode não trazer resultados práticos.

O modelo formulado por HORTON (1940), baseia-se no fenômeno da exaustão, no qual a taxa de variação de uma grandeza em direção a um valor constante decresce à medida que o seu valor atual se aproxima desse valor constante. No caso da infiltração da água no solo ter-se-ia:

$$
\mathrm{di} / \mathrm{dt}=-\mathrm{K}\left(\mathrm{i}-\mathrm{i}_{\mathrm{f}}\right)
$$

Fazendo $i_{0}$ para $t=0$ e integrando-se (08): 


$$
\begin{aligned}
& \int i_{f}^{i} d i /\left(i-i_{f}\right)=\int_{0}^{t} K \cdot d t \text { ou } \\
& \ln \left(i-i_{f}\right)-\ln \left(i_{0}-i_{f}\right)=-K \cdot t \text {, obtendo-se finalmente: } \\
& i_{i}=i_{f}+\left(i_{0}-i_{f}\right) \cdot e^{-K t}
\end{aligned}
$$

onde $\mathrm{K}$ é uma constante relacionada às caracteristicas do solo e que determina o tempo necessário para $\mathbf{i}$ atingir $o$ valor de $i_{f}$, partindo do seu valor inicial $i_{o}$. Uma condição para a validade do modelo é que a chuva (ou irrigação) deve ocorrer com uma intensidade $\mathbf{P}>\mathbf{i}$, contrário do que normalmente acontece nos estágios iniciais de infiltração.

Para eliminar essa restrição, AKAN (1992) propôs uma alteração na equação original, permitindo o seu uso quando $\mathbf{P}<\mathbf{i}$.

Definindo: $\quad I_{e}=\int_{0}^{t}=\left(i-i_{f}\right) \cdot d t$

onde: $\mathbf{l}_{\mathbf{e}}$ é a lâmina infiltrada no solo excedente a $\mathbf{i}_{\mathfrak{f}}$ e resolvendo (09) para $\mathbf{i}$ - $\mathbf{i}_{\boldsymbol{f}}$, temse: $i-i_{f}=\left(i_{0}-i_{f}\right) \cdot e^{-k t}$. Substituindo-se em (10) o valor de $\mathbf{i}-i_{f}$ a partir da equação (09) e integrando-se, tem-se:

$$
\begin{aligned}
& I_{e}=\int_{0}^{t}\left(i_{0}-i_{f}\right) \cdot e^{-k \cdot t} \cdot d t=\left(i_{0}-i_{f}\right) \int_{0}^{t} e^{-k t} \cdot d t=\left(i_{0}-i_{f}\right)\left[-1 / k \cdot e^{-k t}\right]_{0}^{t} \\
& \left(i_{0}-i_{f}\right)\left[-1 / k \cdot e^{-k t}+1 / k\right] \\
& I_{e}=1 / k\left(i_{0}-i_{f}\right)\left(1-e^{-k t}\right)
\end{aligned}
$$

Adotando esse valor de $l_{e}$, é possível demonstrar que a equação (09) é equivalente a:

$$
i=i_{0}-K \cdot l_{e}
$$

em que a velocidade de infiltração diminui linearmente com $\mathbf{l}_{\mathbf{e}}$

$$
\begin{aligned}
& i=i_{0}-\left[k(1 / k)\left(i_{0}-i_{f}\right)\left(1-e^{-k t}\right)\right] \\
& i=i_{0}-\left[\left(i_{0}-i_{f}\right)\left(1-e^{-k t}\right)\right]
\end{aligned}
$$




$$
\begin{aligned}
& i=i_{0}-i_{0}+i_{f}+i_{0} \cdot e^{-k t}-i_{f} \cdot e^{-k t} \\
& i=i_{f}+\left(i_{0}-i_{f}\right) \cdot e^{-k t}
\end{aligned}
$$

Através de experimentos de campo, valores de i podem ser plotados como uma linha reta em papel semilogaritmico de t e a partir desta linha determina-se $\mathbf{k}$. A infiltração acumulada pode ser obtida pela integração da equação (09), obtendo-se:

$$
I=1 / k \cdot\left(i_{0}-i_{f}\right)\left(1-e^{-k t}\right)+i_{f} . t
$$

Uma vantagem do modelo de Horton é que i tende para if quando $t$ tende para o infinito.

Utilizando um modelo aproximado dos postulados de Darcy, GREEN \& AMPT (1911) propuseram uma equação derivada da infiltração da água em uma superfície com uma carga hidráulica constante em um solo homogêneo, com um conteúdo inicial de água uniforme. O modelo de Green e Ampt assume a existência de uma frente de molhamento que separa uma zona úmida que avança de um zona totalmente sêca. O modelo é representado pela relação:

$$
V_{i}=A[1+B(h+W) /]
$$

onde: $\mathbf{W}$ é a carga hidráulica acima da superfície; $\mathbf{h}$ é o potencial mátrico na frente de molhamento e A e B são constantes que dependem do tipo de solo.

A partir da equação de Richards, PHILIP (1957), desenvolveu uma técnica numérica para determinação da velocidade de infiltração, como uma série infinita de termos em potência de $t^{1 / 2}$, onde o coeficiente de cada termo é dependente da difusividade e da capacidade de retenção da água no solo, concluindo pela expressão:

$$
i=0,5 \cdot S \cdot t^{-1 / 2}+C
$$


onde S e C são dependentes do conteúdo inicial da água no solo.

Para tempos demasiadamente longos, C deveria ter um significado semelhante $a i_{f}$ do modelo de Horton, porém Philip verificou que isso não ocorria e como tal a equação (15) tem boa performance para os estágios iniciais da infiltração.

SUTIKTO \& CHIKAMORI (1993) examinaram o comportamento da sortividade em relação às propriedades físicas do solo, tais como conteúdo inicial de água, conteúdo de argila e porosidade; a despeito da aceitação geral de que o conteúdo de água inicial exerce uma grande influência na sortividade, os autores identificaram uma discreta relação entre a sortividade e o conteúdo inicial de água, provavelmente, porque os testes de infiltração foram realizadas em condições de solo úmido.

Estudando a variabilidade espacial da sortividade, SHARMA et alii (1980) identificaram uma dependência linear de $\mathbf{S}$ sobre o conteúdo inicial de água do solo $\left(\Theta_{i}\right)$, medindo a sortividade na mesma área sob 3 (três) condições diferentes de umidade; contudo, análises de variância constataram uma predominância da variabilidade de $\mathbf{S}$ do que de $\Theta_{i}$, sugerindo uma predominância do efeito das propriedades físicas inerentes à distribuição de tamanho dos poros.

HOLTAN (1961) citado por SKAGGS et al.(1969), sugeriu uma equação empírica em que a velocidade de infiltração é expressa em função da infiltração acumulada e da capacidade de armazenagem do solo acima da camada impermeável;

$$
i=a\left[\left(\Theta_{0}-\Theta\right) \cdot L-1\right]^{\omega}+i_{f}
$$


onde $\Theta_{\circ}$ é a umidade de saturação, $\Theta$ é a umidade no início da infiltração; $L$ é a profundidade da camada considerada; e a e $\omega$ são constantes que dependem do tipo de solo e das condições de cultivo.

HUGGINS \& MONKE (1967) descreveram a equação de Holtan adimensionando $\left(\Theta_{\circ}-\Theta\right)$ e introduzindo um parâmetro que quantifica as possibilidades de aumento na taxa de infiltração acima da condição de "steadystate":

$$
i=i_{d} \cdot\left\{\left[\left(\Theta_{0}-\Theta\right) \cdot L-I\right] / \Theta_{0} \cdot L\right\}^{n}+i_{f}
$$

onde $i_{d}=i_{o}-i_{f}$ e $n$ representa a declividade da curva de infiltração.

A equação de Holtan foi desenvolvida para ser aplicada quando a umidade do solo encontra-se entre $\circ$ valor de saturação e o ponto de murchamento. Considerando que $\left[\left(\Theta_{\circ}-\Theta\right) . L-I\right] / \Theta$ varia entre zero e um, $\mathbf{n}$ está relacionado à taxa de redução da velocidade de infiltração com o aumento da umidade do solo.

SKAGGS et alii(1969) desenvolveram uma pesquisa de campo na Universidade de Purdue, USA para avaliar experimentalmente as equações de Green and Ampt, Horton, Philip e Holtan e determinar os valores dos parâmetros para as quatro equações, em quatro condições de solo e conteúdo inicial de água. As quatro equações podem ser usadas para descrição do fenômeno da infiltração, mas as equações de Philip e Green e Ampt estimam a infiltração com taxas bem mais baixas para tempos maiores do que aqueles em que os parâmetros foram obtidos. As equações de Holtan e Horton mostraram forte correlação com os dados experimentais, mesmo para condições de equilíbrio dinâmico. 


\subsection{Evaporação da água do solo.}

Constituindo outro componente importante do ciclo hidrológico, a evapotranspiração é a perda de água do solo e da planta, sob a forma de vapor, para a atmosfera, na unidade de tempo. O fluxo do vapor d'água para a atmosfera varia segundo fatores de ordem meteorológica, fatores do solo e fatores da planta. Quando a umidade do solo não é limitante, o fluxo evaporativo é função somente dos fatores do clima (radiação, temperatura, insolação, umidade e ventos) (DOORENBOS \& PRUITT, 1977).

De outra maneira, pode-se dizer que a evaporação da água do solo, sofre influência de 3 (três) fatores: quantidade de energia disponivel para conversão da água líquida em vapor, natureza da interface solo-ar e a umidade do solo. Em regiões áridas e semi-áridas que apresentam baixas precipitações pluviométricas, altas temperaturas diurnas do ar e do solo, normalmente associadas com boa disponibilidade de energia solar, a camada superficial do solo pode apresentar baixos níveis de umidade $\left(0.06 \mathrm{~cm}^{3} \cdot \mathrm{cm}^{-3}\right.$ na Fazenda Experimental do Vale do Curu, em Pentecoste-Ce no mês de setembro) e assim o fluxo evaporativo pode deixar de ocorrer na superficie. A interface líquido-vapor, chamada frente de evaporação, nestas circunstâncias ocorrerá no interior do perfil do solo. O processo dominante do transporte do vapor acima da frente de evaporação é o transporte de massa, assim como o fluxo de água líquida abaixo da frente de evaporação. Uma abordagem mais detalhada sobre a determinação da frente de evaporação no interior do perfil do solo é encontrada em BASTIAANSSEN et alii (1989). 
O cálculo da evaporação da água do solo envolve muitas dificuldades. A variação da evaporação se constata tanto do ponto de vista espacial como temporal; em cada ponto de uma determinada área, a evaporação apresenta valores diferentes ao longo do dia. Portanto, sob a ótica pontual, parece não haver muitos problemas, porém quando se necessita a integração em relação ao tempo e ao espaço para se obter taxas válidas para um período e área maiores, surgem as complicações.

O vapor d'água não se distribui no ar de forma homogênea e por isso, os valores medidos variam em função do valor inicial e das propriedades do ar que escoa para fora da área estudada .

O transporte de água da superfície para a atmosfera é influenciado pelo vento, com o fator de proporcionalidade devendo ser medido a partir de dados de velocidade, da rugosidade da superfície, estabilidade atmosférica, o que sem dúvida deve constituir um empecilho, embora muitas relações empíricas para uso local tenham sido determinadas com a ajuda de lisímetros.

Estudos dos efeitos das variações temporais dos fatores climáticos sobre a evaporação, têm mostrado que a influência da radiação solar sobre a variação diária na evaporação medida em superfície de água livre, tem alcançado até $70 \% ; 35 \%$ para temperatura máxima e mínima do ar e 50 a $65 \%$ para variação diária da velocidade do vento (DAVENPORT, 1967). A evapotranspiração normalmente é tratada sob duas formas: evapotranspiração potencial (ETP) e evapotranspiração real (ETR). A evapotranspiração potencial se refere ao limite máximo da evapotranspiração de um conjunto solo-planta, sob determinadas condições de solo, 
da planta e da atmosfera. Há uma vasta literatura que aborda o problema conceitual do termo. THORNTHWAITE (1948) definiu como sendo a perda de água verificada em uma superfície completamente coberta com vegetação, sem limitação de umidade no solo à disposição dessa vegetação. DOORENBOS \& PRUITT (1977), definiram como a taxa de evapotranspiração de uma superfície extensa, coberta com grama de altura uniforme entre 8 e $15 \mathrm{~cm}$, em pleno desenvolvimento, completamente sombreada e sem limitações de umidade no solo, consagrando o termo evapotranspiração de referência.

A evapotranspiração real é a perda de água do solo e da planta para a atmosfera, sob quaisquer condições de cobertura vegetal e de disponibilidade hídrica do solo.

Há uma extensa lista de modelos e procedimentos para a medida ou estimativa da evapotranspiração.

O Tanque Classe A foi adotado pela World Meteorological Organization e a International Association of Scientific Hydrology como um instrumento de referência para o ano geofísico internacional. É o método mais difundido para a estimativa da evapotranspiração, baseado na hipótese de que há uma correlação positiva entre a evaporação do tanque (EV) e a evapotranspiração de uma superfície vegetada. É um tanque cilíndrico de ferro galvanizado n 14 , com 1,21m de diâmetro e $25,4 \mathrm{~cm}$ de profundidade, assentado sobre um estrado de madeira, a $15 \mathrm{~cm}$ do solo, cujo nível de água é medido através de um micrômetro de gancho com o apoio de um poço tranquilizador. 
A medida do tanque guarda uma associação estreita com a evapotranspiração potencial se o solo encontra-se na capacidade de campo. A conversão da evaporação do tanque para o valor de ETP é feita multiplicando-se EV por um fator $K_{p}$, chamado coeficiente do tanque, que depende da umidade do ar, da velocidade do vento e da área tampão (DOORENBOS \& PRUITT,1977).

A lisimetria hoje vem sendo bastante utilizada para medir diretamente a ETP, em que cada componente do balanço hídrico é medido e a evaporação é obtida com uma precisão já alcançada de $0.05 \mathrm{~mm}$, pela redução de pêso do lisímetro.

Um tipo de lisímetro também chamado de evapotranspirômetro, construído de alvenaria ou cimento-amianto, com um sistema de drenagem, que procura manter a variação do armazenamento nula, tem dado bons resultados para medidas em períodos longos de observação (PEREIRA, 1992).

A evaporação do solo sem vegetação pode ser estimada com a utilização da solução da equação do fluxo insaturado, numa só dimensão, sob condições isotérmicas num perfil homogêneo e com umidade inicial uniforme (BLACK et al.1969). A equação e as condições de contôrno são:

$$
\begin{aligned}
& \partial \Theta / \partial t=\partial / \partial z \cdot[D(\Theta) . \partial \Theta / \partial z] \\
& \Theta=\Theta_{i,} \quad z \geq 0, \quad t=0 \\
& \Theta=\Theta_{s}, \quad z=0, \quad t>0
\end{aligned}
$$

onde $\Theta$ é o conteúdo de água, $\mathbf{z}$ a distância e $\mathrm{D}(\Theta)$ a difusividade da água no solo.

CRANK (1956) resolveu analiticamente a equação (18) em função do fluxo q conforme a relação:

$$
q=\left(\Theta_{i}-\Theta_{0}\right)\left(D / \pi^{2}\right)^{1 / 2}
$$


onde $\Theta_{\mathrm{i}}$ é o conteúdo inicial de água, constante para $\mathbf{t}=0$ e $\mathbf{z} \geq 0, \Theta_{\mathrm{s}}$ é o conteúdo de água em $\mathbf{z}=0$, constante para $\mathbf{t}>0$. A integral da equação (19) em relação ao tempo dá a evaporação acumulada $\mathbf{E}$ :

$$
E=2\left(\Theta_{i}-\Theta\right)(D . t \pi)^{1 / 2}
$$

Um procedimento bastante utilizado para o cálculo da evaporação em um determinado período é através do balanço hídrico, desde que sejam conhecidos os fluxos de entrada de água no solo (chuva/irrigação), os fluxos de saida (drenagem profunda e escoamento superficial) e a variação do armazenamento da água no solo, embora que em certas circunstâncias possam ocorrer imprecisões devido, principalmente, à variabilidade das propriedades da maioria dos solos. 


\section{MATERIAL E MÉTODOS}

\subsection{Descrição do modelo}

O MUSAG (Modelo de Umidade do Solo para Atividades Agrícolas) utiliza, basicamente a equação do balanço hídrico, para um intervalo de 1 (um) dia, na seguinte forma:

$$
\begin{aligned}
& A r m_{f}=A r m_{i}+I-Q-E \\
& R=P-1
\end{aligned}
$$

onde $\operatorname{Arm}_{\mathfrak{f}}$ e $\mathbf{A r m}_{\mathrm{i}}$ são os armazenamentos final e inicial do solo no intervalo de 1 (um) dia; I é o volume infiltrado; $\mathbf{Q}$ é o volume percolado; E é o volume evapotranspirado; uma vez que o modelo foi desenvolvido para solos sem vegetação, E é equivalente ao volume evaporado pelo solo; $\mathbf{R}$ é o volume escoado e P é a precipitação ocorrida durante o dia.

As variáveis infiltração e percolação são avaliadas com base nas características do solo e na quantidade de água disponível em um determinado momento $(\Theta)$. Essas funções são representadas pelas seguintes equações:

$$
\begin{aligned}
& i=i_{f}+\left(i_{0}-i_{f}\right)[(C C-\Theta) / C C]^{\alpha} \\
& q=i_{f}\left(\Theta / \Theta_{0}\right)^{\beta}(24)
\end{aligned}
$$


para $0 \leq \Theta \leq C C$, onde i é a capacidade de infiltração do solo $\mathrm{mm} / \mathrm{dia}$; if é a capacidade máxima de percolação profunda em mm/dia; i i é capacidade máxima de infiltração do solo em mm/dia; $C$ é a capacidade máxima de retenção de água não gravitacional contida na parcela no primeiro metro de profundidade, em mm(nos casos de solos com profundidade menor que um metro, foi tomada toda a profundidade do solo (ANDRADE, 1995); $\Theta$ é o estado atual de umidade do solo, em mm; q é a capacidade de drenagem interna, em mm; $\alpha$ e $\beta$ são parâmetros de ajuste da variabilidade da infiltração e da percolação com a umidade do solo, respectivamente (ANDRADE, 1995)

Para a avaliação da evaporação, além das características do solo e da umidade disponivel, são consideradas também as condições climáticas representadas pela evapotranspiração potencial, obtida a partir de dados de evaporação medida em Tanque Classe A, conforme a equação seguinte:

$$
E V=E V P(\Theta / k \cdot C C)^{\gamma}
$$

para $0 \leq \Theta \leq k . C C$. Se $C C \geq \Theta>k . C C, E V=E V P$, onde EV é a evaporação real, em $\mathrm{mm} / \mathrm{dia}$; EVP é a evapotranspiração potencial, em mm/dia; $\mathbf{k}$ é um coeficiente cujo valor varia de 0 a 1,0 que indica em que umidade do solo já ocorre a evapotranspiração em nível potencial, e $\gamma$ é um parâmetro indicativo da variação de EV com a umidade do solo (ANDRADE, 1995).

Segundo ANDRADE (1995), os valores de CC foram obtidos com dados da Superintendência do Desenvolvimento do Nordeste (SUDENE) e a partir desses valores, foram determinados os parâmetros relativos à capacidade máxima de infiltração ( $\mathbf{i}_{0}$ ), enquanto os dados de $\mathbf{i}_{f}$ foram obtidos com base no Mapa Geológico 
do Estado do Ceará; quanto aos valores de $\alpha, \beta$ e $\gamma$, para a sua determinação foram utilizados dados fluviométricos para as bacias em que esses dados eram conhecidos e na ausência desses dados, foram compatibilizados com os resultados da equação de regionalização de deflúvios, desenvolvida durante a elaboração do Plano Estadual de Recursos Hídricos.

O cálculo da umidade para o dia i+1 segue o seguinte procedimento:

- a partir da umidade de um certo dia $\left(\Theta_{i}\right)$, é calculada a capacidade de infiltração do solo $\mathbf{i}_{\mathbf{i}}$ (Equação 23);

- admitindo que ocorra uma chuva e que o seu volume infiltre totalmente, soma-se à $\Theta_{\mathrm{i}}$ O total da precipitação P ocorrida no intervalo de tempo i a i+1 (1 dia), obtendo-se $\Theta_{i+1}$

- com base no valor de $\Theta_{i+1}$, é calculada a nova capacidade de infiltração do solo $\mathbf{i}_{i+1}$

- se $\mathbf{i}_{\mathbf{i}}>\mathbf{P}$ e $\mathbf{i}_{\mathbf{i + 1}}>\mathbf{P}$, não haverá escoamento e $\Theta_{\mathbf{f}}$ é calculada pela equação (21), onde Q e E são calculados pelas equações (24) e (25), utilizando-se os valores médios de $\Theta_{i}$ e $\Theta_{i+1} ;$ e

- nos demais casos, o valor de $\mathbf{i}_{\mathrm{i}}$ é calculado por processo iterativo até o alcance da convergência dos valores de $\mathbf{i}_{i+1}$ e $\Theta_{i+1}$, sendo $\Theta_{\mathfrak{f}}$ atualizada pela equação (21), incorporando os valores de Q e E calculados de forma idêntica à anterior.

Levando em conta as dificuldades de medir a umidade do solo em todos os municípios, em um determinado dia, foi escolhido o dia 10. de outubro de cada ano para inicializar o modelo, assumindo $\Theta_{\mathrm{i}}=0$ neste dia para todo o Estado do Ceará. 
Essa decisão se explica por serem os meses de setembro e outubro os mais secos do ano; embora no dia 10.de outubro a umidade não seja rigorosamente zero, é presumido que no início de janeiro de cada ano (período em que o modelo começa a ser utilizado) a umidade estimada esteja bastante próxima da realidade.

Além da estimativa de umidade para embasar as decisões de plantio, do MUSAG são derivados outros produtos relacionados à previsão de deficits hídricos para as culturas anuais, ao cálculo do escoamento superficial em bacias hidrográficas e à disponibilidade hídrica para as culturas do milho e do feijão, temas esses fora do escopo do presente trabalho.

\subsection{Caracterização da área da pesquisa.}

A pesquisa foi desenvolvida em área da Fazenda Experimental do Vale do Curu (FEVC), pertencente ao Centro de Ciências Agrárias da Universidade Federal do Ceará, no município de Pentecoste entre os paralelos $3^{\circ} 45^{\prime}$ e $3^{\circ} 50^{\prime}$ de latitude sul e os meridianos $39^{\circ} 15$ e $39^{\circ} 20^{\prime}$ longitude oeste, a $115 \mathrm{~km}$ da cidade de Fortaleza, a uma altitude de $47 \mathrm{~m}$.

Segundo a classificação de Thornthwaite, o clima da região é do tipo semiárido $D$, com índice efetivo de umidade igual a $-42,3$ com uma precipitação média anual de $750 \mathrm{~mm}$, sendo que $76 \%$ das chuvas ocorrem no período de fevereiro a maio, enquanto $75 \%$ da evaporação acontece no período de julho a janeiro (MARCA, 1985; SILVA, 1987).

A temperatura média do ar é da ordem de $27^{\circ} \mathrm{C}$, alcançando as máximas $32,8^{\circ} \mathrm{C}$ e as mínimas $22,1^{\circ} \mathrm{C}$. 
O solo da área pertence à Unidade Serrote Grande com declive de 0 a $3 \%$, tendo como material originário saprolitos de gnaisse, apresentando pedregosidade, erosão do tipo laminar, moderadamente drenado e vegetação do tipo caatinga hiperxerófila, composta por indivíduos xerófilos lenhosos deciduais, predominando o marmeleiro, mofumbo, jurema, catingueira, pau-branco e sabiá. Pertence à classe Bruno não cálcico, raso $(83 \mathrm{~cm})$ com uma sequência de horizontes $A_{p}$, com espessura de $45 \mathrm{~cm}$ e $B_{t}$ com espessura de $38 \mathrm{~cm}$, textura arenosa no primeiro e argilosa no segundo, apresentando descontinuidade em relação à natureza do material originário, entre o horizonte superficial e o subsuperficial; apresenta reação ácida a moderadamente ácida, coloração bruno acinzentada escura. $O$ horizonte $A_{p}$ apresenta estrutura maciça, ligeiramente duro quando seco e muito friável quando úmido. O horizonte $B_{t}$ tem coloração vermelho-amarelada, com estrutura moderada pequena, blocos subangulares, duro quando seco e muito friável quando úmido (FUNCEME, 1995). Os Bruno não cálcicos representam 17,91 dos solos do Estado do Ceará, ocupando a terceira posição, enquanto os podzólicos e latossolos, estão em primeiro e segundo lugar, respectivamente (Figura 1).

A área delimitada para a pesquisa foi de $80 \mathrm{~m} \times 120 \mathrm{~m}$, praticamente plana, mantida sem vegetação durante todo o período de determinação da umidade do solo; nos últimos 5 (cinco) anos foi cultivada com culturas anuais, predominantemente o caupi (Vigna unguiculata L. Walp).

A análise granulométrica, a determinação da densidade da partícula e análise química, foram realizadas no Laboratório de Solos do Centro de Ciências Agrárias da Universidade Federal do Ceará, em Fortaleza, enquanto a determinação das 


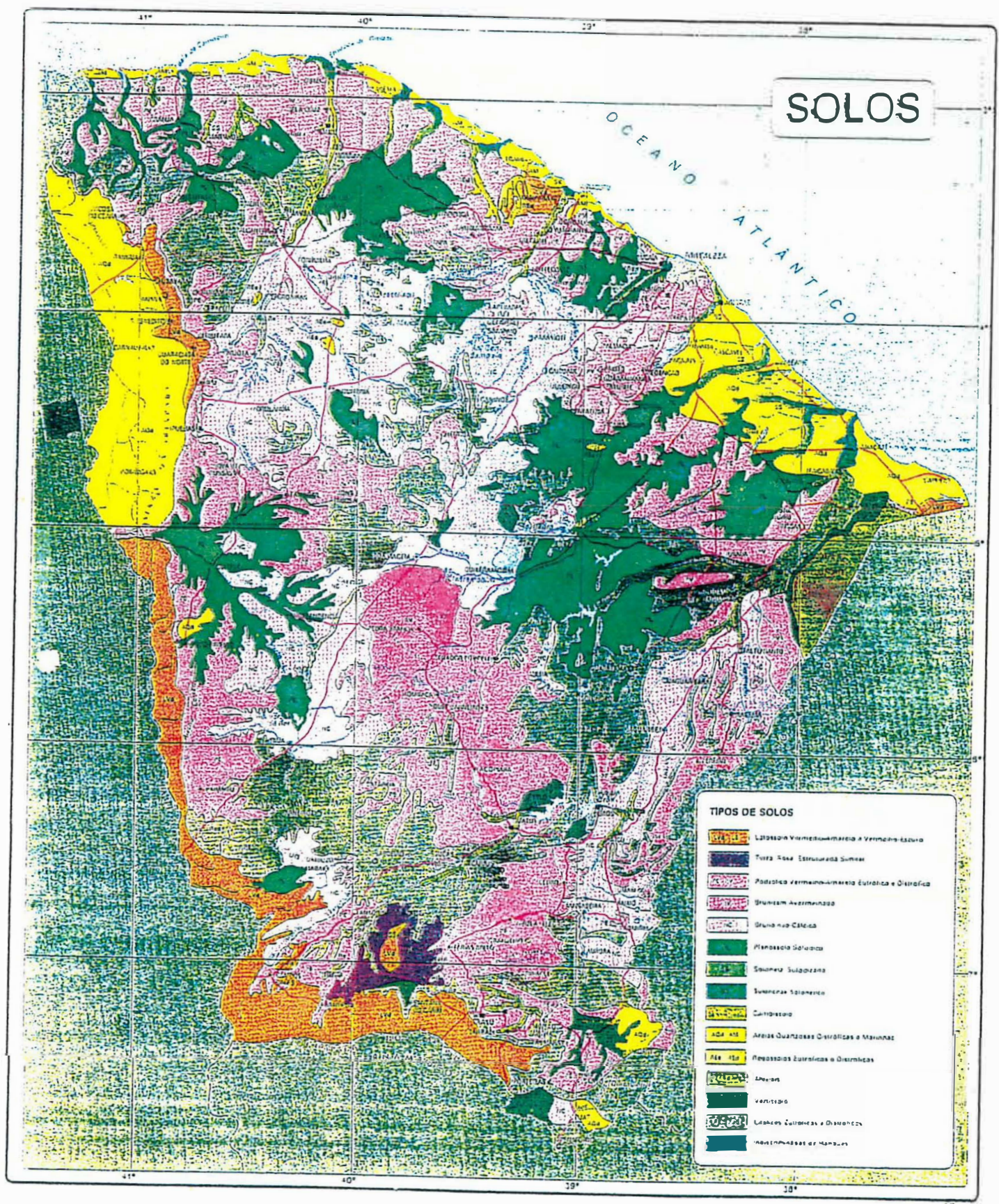

Figura 1. Tipos de solos do Estado do Ceará. Fonte: Fundação Instituto de Planejamento do Ceará, 1995. 
curvas de retenção foram realizadas no Laboratório de Irrigação do Departamento de Engenharia Rural da Escola Superior de Agricultura "Luiz de Queiroz" (ESALQ), em Piracicaba, SP.

Para determinação da densidade do solo, foram abertas 8(oito) trincheiras (a

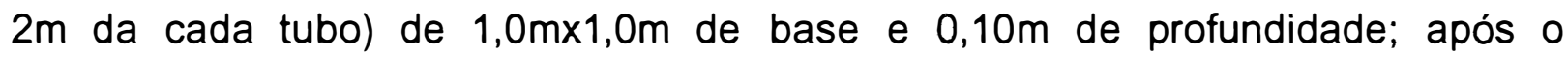
nivelamento do fundo da escavação, foram retiradas amostras com o cilindro de Uhland correspondentes à primeira camada $(0-20 \mathrm{~cm})$.

Em seguida a trincheira foi aprofundada até $0,30 \mathrm{~m}$, novamente nivelada para retirada das amostras referentes a camada de 20 a $40 \mathrm{~cm}$. Esse procedimento se repetiu até a profundidade de $90 \mathrm{~cm}$, para retirada das amostras da última camada (80 a 100cm). Os cilindros foram acondicionados em papel alumínio para armazenamento e transporte para o laboratório (BLAKE \& HARTGE, 1986).

\subsection{Determinação da umidade do solo e dos gradientes de potencial}

A medida da umidade do solo foi realizada diariamente no período de 11/02/95 a 30/06/95, com o uso de uma sonda de neutrons TROXLER Série 3300 com fonte Amerício-Berilio (10 mCi Am-241: Be com produção de 25.000 neutrons/segundo), encapsulamento duplo em aço inoxidável de fabricação norteamericana. Foram instalados 8 (oito) tubos de acesso como mostra a Figura 2, e as contagens dos neutrons moderados feitas às profundidades de $20 \mathrm{~cm}, 40 \mathrm{~cm}, 60 \mathrm{~cm}$, $80 \mathrm{~cm}$ e $100 \mathrm{~cm}$, com 3 ( três ) repetições, obtendo-se assim a contagem média $\left(\mathrm{C}_{\mathrm{m}}\right.$ ); a contagem padrão ( $\left.C_{1}\right)$ foi determinada em água em tempo longo ( 4 minutos ); na determinação das curvas de calibração foram adotados os seguintes procedimentos: 


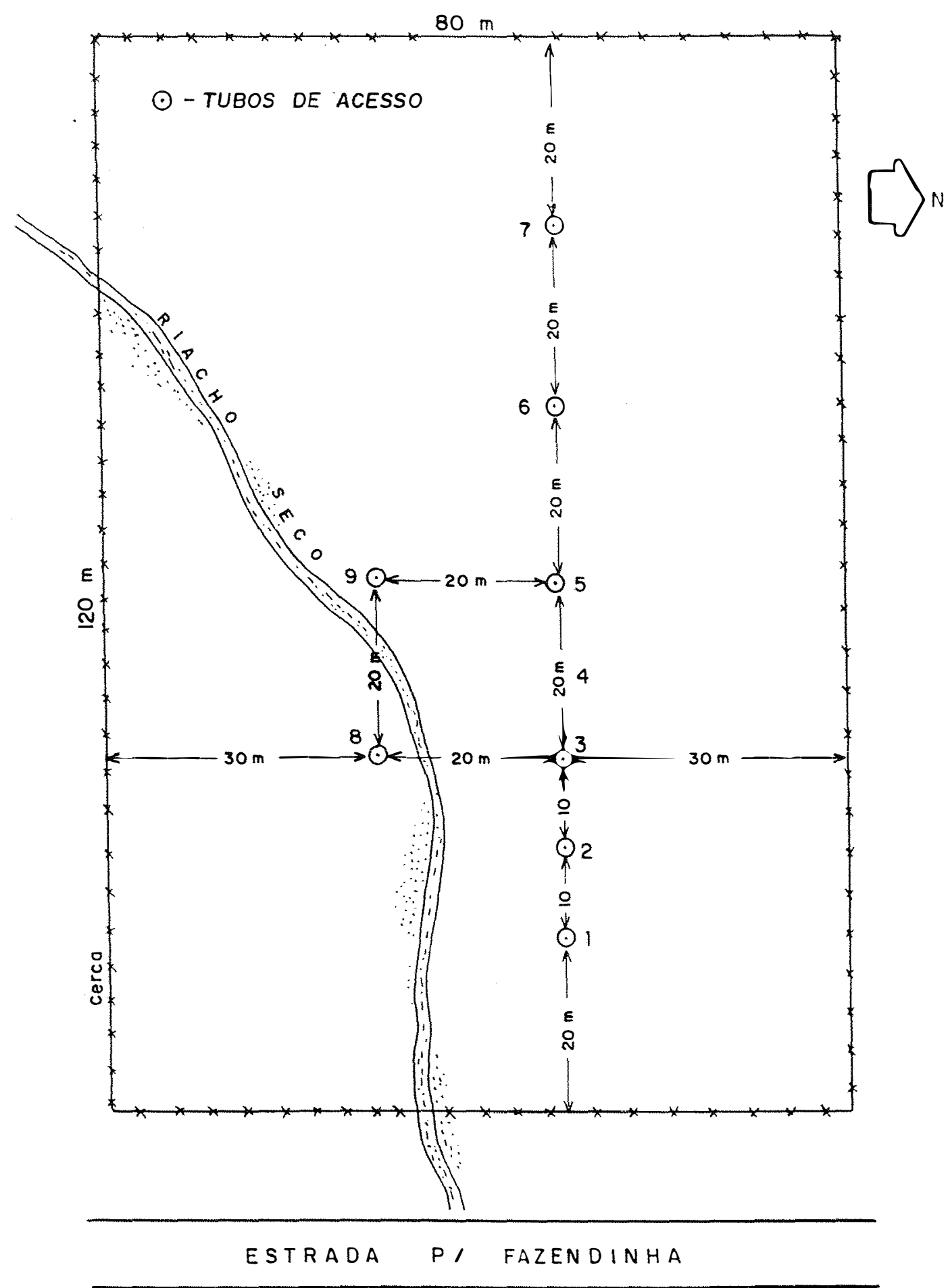

Figura 2. Distribuição de tubos de acesso na área experimental, Pentecoste-Ce, 1995. 
- delimitou-se uma área de $4 \mathrm{~m} \times 4 \mathrm{~m}$ ao redor de cada tubo, com lâminas de ferro, umedecendo-se o solo até a profundidade de 1,0 m próximo à saturação, ocasião em que foi efetuada a primeira leitura de $C_{m}$ e retiradas amostras de solo a um raio médio de $40 \mathrm{~cm}$ em redor da sonda, para determinação da umidade por gravimetria, para todas as profundidades;

- à medida que o solo ia secando por evaporação ou percolação profunda, novas leituras de $\mathrm{C}_{\mathrm{m}}$ foram realizadas e novas amostras de solo foram coletadas, até o atingimento de uma umidade mínima possível;a partir dos dados de $C_{m} / C_{L}$ como variável independente e de umidade correspondente, como variável dependente, de todos os tubos, foram ajustadas as curvas de calibração para cada profundidade, através de regressão linear da forma:

$$
\Theta=a+b\left(C_{m} / C_{L}\right)
$$

Para obtenção da umidade medida a fim de se comparar com a umidade estimada pelo modelo, utilizou-se a equação (26) para cada profundidade, sendo $\mathbf{C}_{m}$ a média das leituras da sonda de 6 (seis) tubos, $C_{L}$ a contagem padrão em água, a e b, os coeficientes linear e angular da curva de calibração, respectivamente.

Os valores de armazenamento médio até a profundidade de $100 \mathrm{~cm}$ e os erros decorrentes foram calculados pelo método numérico de integração de Simpson ( LEITHOLD, 1986), de acordo com a equação (27) por ser mais preciso, quando comparado, por exemplo, com o método trapezoidal (TURATTI \& REICHARDT, 1991).

$$
\begin{aligned}
& \int f(\Theta) \mathrm{d} \Theta \approx 1 / 3 . \Delta \mathrm{z}\left[f\left(\Theta_{0}\right)+4 . f\left(\Theta_{1}\right)+2 . f\left(\Theta_{2}\right)+4 . f\left(\Theta_{3}\right)+2 . f\left(\Theta_{4}\right)+\ldots+\right. \\
& \text { 2. } f\left(\Theta_{2 n 2}\right)+\quad+4 . f\left(\Theta_{2 n-1} f\left(\Theta_{2 n}\right)\right.
\end{aligned}
$$


onde $\Theta$ é a umidade, $\mathbf{n}$ é o número de vezes que a regra de Simpson é aplicada e $\Delta \mathbf{z}$ é o intervalo vertical entre as medidas da umidade.

Para a obtenção dos gradientes de potencial mátrico (dh/dz), foram instaladas 8 (oito) baterias de 6 (seis) tensiômetros de mercúrio (uma para cada tubo de acesso, colocada a $40 \mathrm{~cm}$ deste), às profundidades de $10,30,50,70,90$ e $110 \mathrm{~cm} \mathrm{e}$ utilizadas as seguintes expressões:

$$
\begin{aligned}
& h_{z}=-12,6 \cdot h_{g}+h_{c}+z \\
& d h / d z=\left[\left(h_{z-10}\right)-\left(h_{z+10}\right)\right] / 20
\end{aligned}
$$

onde: $\mathbf{h}_{\mathbf{z}}$ é o potencial mátrico $\left(\mathrm{cm} \mathrm{H}_{2} \mathrm{O}\right)$ à profundidade $\mathbf{z}(\mathrm{cm}) ; \mathbf{h}_{\mathbf{g}}$ é a altura da coluna de mercúrio $(\mathrm{cm})$; e $\mathbf{h}_{\mathrm{c}}$ é a distância do nivel de mercúrio na cuba à superfíce do solo. O gradiente de potencial mátrico da área como um todo foi obtido calculando-se a média dos potenciais mátricos determinados pelas baterias associadas a cada tubo. O gradiente de potencial total $(\mathbf{H})$ foi obtido somando-se o gradiente de potencial gravitacional ao gradiente de potencial mátrico e desprezando-se a influência dos demais potenciais (térmico, elétrico, osmótico, etc). As leituras de $h_{g}$ foram feitas diariamente.

\subsection{Determinação dos parâmetros de infiltração, percolação e evaporação}

Na determinação dos parâmetros $\mathbf{i}_{0}$ e if utilizou-se um conjunto de cilindros infiltrômetros concêntricos com $30 \mathrm{~cm} \mathrm{e} 60 \mathrm{~cm}$ de diâmetros, enterrados no solo até $10 \mathrm{~cm}$ e com uma carga hidráulica constante de $10 \mathrm{~cm}$ no cilindro interno.

Por ocasião da determinação da condutividade hidráulica, realizada nos meses mais secos do ano (setembro/outubro), foram feitos 3 (três) testes de 
infiltração ao redor de 6 (seis) dos 8 (oito) tubos, em uma área de $16 \mathrm{~m}^{2}$, para verificar a relação entre a velocidade e o tempo de infiltração, com o objetivo de se ajustar uma equação segundo o modelo de Kostiakov. Para efeito do teste, considerou-se $I_{0}$, a velocidade de infiltração registrada no primeiro minuto de cada teste (BOWER, 1986). No avaliação da infiltração, $\mathbf{i}_{\mathbf{f}}$ correspondeu ao valor de $\mathbf{i}$ quando o perfil alcançou a condição de saturação. A duração média desses testes foi de 5,4 horas.

Para determinação da capacidade de campo, em redor de cada tubo de acesso foi delimitada uma área de $4 \mathrm{~m} \times 4 \mathrm{~m}$, saturada até a profundidade de $100 \mathrm{~cm}$, determinando-se a umidade nesse momento $\Theta_{0}$ e em seguida coberta com um plástico para evitar fluxos de água entre o solo e a atmosfera. A cada 24 horas foram retiradas amostras às profundidades de $20,40,60,80$ e $100 \mathrm{~cm}$ e determinada a umidade por gravimetria, até se obter peso constante, com um período mínimo de 96 horas, tomando-se esse valor como a capacidade de campo, para cada profundidade.

Para subsidiar as estimativas da evapotranspiração potencial (ETP) e as medidas da precipitação pluviométrica, foram instalados na área da pesquisa um Tanque Classe A, um anemômetro de canecas a $2 \mathrm{~m}$ de altura e um pluviômetro tipo Ville de Paris. Os dados de umidade relativa do ar foram obtidos na Estação Meteorológica da FEVC, localizada a $2,0 \mathrm{~km}$ da área experimental.

As leituras do anemômetro e do tanque foram feitas diariamente às 9:00 $\mathrm{h}$, sendo estas corrigidas em função da umidade relativa do ar, da velocidade do vento e das condições de exposição do tanque, para obtenção da ETP(DOORENBOS \& 
PRUITT, 1977); as medidas da precipitação pluviométrica foram feitas às 9:00 h e 15:00 h, também diariamente.

Para a determinação de $\alpha$ da equação (23), procedeu-se para cada tubo a determinação em campo da relação $\mathrm{i}(\Theta)$ através de testes de infiltração, medindo-se i no primeiro minuto do teste e simultaneamente $\Theta$, sempre na camada superficial, inicialmente com o solo no seu nivel de umidade mais baixo do período experimental; em seguida, saturou-se o solo repetindo-se o teste; dai para a frente, à medida que o solo ia secando, novos valores de $\mathbf{i}$ foram obtidos para diferentes valores de $\Theta$. Com os dados de i e $\Theta$ de todos os tubos e adotando-se o valor de $\Theta_{0}$ ao invés de CC na equação (23), plotou-se $\log \left(\mathbf{i}-\mathbf{i}_{f}\right)$ versus $\log \left(\Theta_{0}-\Theta / \Theta_{0}\right)$, determinando-se $\alpha$.

Com os valores de $K(\Theta)$, dos gradientes verticais do potencial hidráulico e da umidade medidos ao longo do período experimental, para cada profundidade, obteve-se os valores das perdas por percolação profunda q; plotando-se os valores de log q versus $\log \left(\Theta / \Theta_{\circ}\right)$, desenvolveu-se uma regressão linear, transformando-se a equação (24) em:

$$
\log q=\log l_{f}+\beta \cdot \log \left(\Theta / \Theta_{0}\right)
$$

onde $\beta$ é o coeficiente angular da equação, correspondente ao coeficiente $\beta$ na equação (24)

A condutividade hidráulica $K(\Theta)$ para as diversas profundidades estudadas, foi determinada pelo método de LIBARDI et al.(1980),conforme a equação: 


$$
K(\Theta S)=K_{0} \cdot e^{\lambda(\Theta-\Theta 0)}
$$

onde: $K_{0}$ é a condutividade hidráulica na condição de saturação e $\lambda$ é uma constante que depende das características do solo.

A determinação de $\mathrm{K}(\Theta)$ consistiu em se delimitar uma área de $4 \mathrm{~m} \times 4 \mathrm{~m}$ com lâminas de ferro, instalando-se uma bateria de tensiômetros às profundidades de 10 , $30,50,70,90$ e $100 \mathrm{~cm}$ e um tubo de acesso para sonda de neutrons; colocou-se água, mantendo-se uma carga hidráulica constante de $10 \mathrm{~cm}$ até que as leituras da coluna de mercúrio nos tensiômetros e da contagem média de neutrons na sonda, ficassem aproximadamente constantes, evidenciando a saturação do perfil; após a garantia de que o fluxo alcançou a condição de "steady-state", foi interrompido o fornecimento de água e após a infiltração da lâmina, cobriu-se a superficie com um plástico, fazendo-se em seguida a primeira leitura dos tensiômetros e da sonda $(t=0)$, o que foi repetido durante aproximadamente 30 (trinta) dias para as profundidades de $20,40,60,80$ e $100 \mathrm{~cm}$; de posse dos dados de $\Theta$ e t para cada profundidade, desenvolveu-se uma análise de regressão linear entre $\left(\Theta_{0}-\Theta\right) \times \ln \mathbf{t}$ e entre $\left(\Theta_{0 m}-\Theta_{m}\right) x$ in t. Os coeficientes angulares dessas curvas é $1 / \lambda$ e $1 / \lambda_{m}$, respectivamente, de acordo com as equaçōes:

$$
\begin{aligned}
& \Theta_{0}-\Theta=1 / \lambda \ln t+1 / \lambda \cdot \ln \left(\lambda \cdot K_{0} / a \cdot z\right) \\
& \Theta_{0 m}-\Theta_{m}=1 / \lambda_{m} \ln t+1 / \lambda_{m} \cdot \ln \left(\lambda_{m} \cdot K_{0} / z\right)
\end{aligned}
$$

onde: $\Theta_{o m}$ é a umidade média de saturação do perfil, $\Theta_{m}$ é a umidade média até a profundidade $z$ e $a=\lambda / \lambda_{m}$. Calculando-se $K_{0}$ a partir de (32) e com o valor de $1 / \lambda$, chega-se à equação (03). 
Finalmente, para determinação de $\mathbf{k}$ e $\gamma$ na equação (25), plotou-se os dados de $\log E V$ e log $\left(\Theta / \Theta_{0}\right)$ para cada profundidade, obtendo-se a equação:

$$
\log E V=\log \left(E T P / k^{\gamma}\right)+\gamma \cdot \log \left(\Theta / \Theta_{0}\right)
$$

Os valores de EV foram obtidos através do balanço hídrico nos dias sem chuva segundo a equação:

$$
E=\operatorname{Arm}_{i-1}-\operatorname{Arm}_{i}-Q
$$

onde $\operatorname{Arm}_{i}$ é o armazenamento no perfil de 1,0 metro no dia i e $\operatorname{Arm}_{i-1}$ é o armazenamento no perfil de 1,0 metro no dia anterior. Como o valor de ETP é conhecido, facilmente se obtem $\mathbf{k}$ e $\gamma$.

\subsection{Procedimentos para avaliação do MUSAG}

Os principais parâmetros da estatística clássica utilizados por diversos pesquisadores em avaliação de modelos, são o desvio médio e o desvio padrão da estimativa (CLEMENTE et alii., 1994; WORKMAN \& SKAGGS, 1989; SKAGGS, 1982; CHANG et alii. 1983). A inclusão do coeficiente de correlação e do coeficiente de variação também tem sido considerada mais recentemente(FARIA et alii. 1982; ZEPP \& BELZ, 1992).

O desvio padrão $(\sigma)$ dá uma medida de dispersão dos valores de umidade estimados em relação aos valores observados, em unidades da medida original, ao passo que a variância $\left(\sigma^{2}\right)$ identifica a dispersão elevada ao quadrado; por isso, segundo LIBARDI et alii.(1996) deve-se preferir $\sigma$ a $\sigma^{2}$.

O desvio médio e o desvio relativo podem ser usados para quantificar o grau de subestimativa ou superestimativa de um modelo em relação aos dados medidos 
em campo, alem de não serem tão sensíveis aos "outliers" como o coeficiente de variação (CLEMENTE et alii., 1994; ZEPP \& BELZ, 1992). Por outro lado, o coeficiente de variação apresenta a vantagem de avaliar a dispersão dos dados em relação à média, independentemente das unidades utilizadas, facilitando comparar graus de dispersão entre variáveis de natureza diferentes (LIBARDI et alii.,1996).

Define-se assimetria como sendo o grau de afastamento da simetria de uma distribuição, enquanto a curtose avalia o grau de achatamento de uma curva em relação à distribuição normal (SPIEGEL, 1977).

No presente estudo, foi feita uma análise preliminar para verificar o grau de variabilidade das medidas de umidade realizadas, pela sonda de neutrons entre os diversos tubos, durante o período experimental, através da média $\left(\Theta_{m}\right)$, desvio padrão $(\sigma)$ e coeficiente de variação $\left(\mathbf{C V}_{\Theta}\right)$, segundo as equações:

$$
\begin{aligned}
& \Theta_{m}=\Sigma \Theta_{i} / N \\
& \sigma_{\Theta}=\left[\Sigma\left(\Theta_{i}-\Theta_{m}\right)^{2}\right]^{0.5} \\
& \mathrm{CV}_{\Theta}=\sigma_{\Theta} / \Theta
\end{aligned}
$$

onde $\Theta_{i}$ é a umidade medida no tubo i e $\mathbf{N}$ é o número de tubos utilizados.

$\mathrm{Na}$ estatística clássica pressupõe-se que as amostras sejam independentes e que possuam distribuição normal. Por isso, foi feita a verificação da normalidade através dos coeficientes de assimetria $(\mathbf{C s})$ e curtose $(\mathbf{C r})$, através das equações:

$$
\begin{aligned}
& \mathrm{Cs}=\left(\mathrm{d}_{\mathrm{m}}-\mathrm{Mo}\right) / \sigma \\
& \mathrm{Cr}=\mathrm{M}_{4} / \sigma^{4}
\end{aligned}
$$


onde $\mathbf{d}_{\mathbf{m}}$ é o êrro médio, Mo é a moda, $\sigma$ é o desvio padrão $\boldsymbol{M}_{4}$ é o momento de quarta ordem em relação à média e $\sigma^{4}$ é o quadrado da variância, tanto para valores estimados como para valores observados.

Outro procedimento adotado para testar a normalidade dos dados, foi o traçado da "reta de Henry", que consistiu em classifica-los em ordem crescente de valores, calcular as frequências acumuladas, e plotá-los em um dos eixos de uma folha de "papel de probabilidade normal", enquanto no outro eixo de escala aritmética, foram plotados os valores observados, e verificando-se o quanto êsse gráfico se aproxima de uma reta, para se concluir sobre a normalidade da distribuição. No traçado do gráfico e na avaliação da linearidade deve-se sempre considerar que os valores observados são aleatórios e como tal, nunca se comportarão como um linha reta perfeita.

Para a avaliação do MUSAG propriamente dita, comparou-se os valores do armazenamento medidos em campo com os valores estimados pelo modelo, no periodo experimental, através da análise estatística clássica, compreendendo o cálculo do desvio médio $\left(\mathbf{d}_{\text {me }}\right)$, desvio relativo $\left(\mathbf{d}_{\mathbf{r e}}\right)$, desvio padrão $(\sigma)$, coeficiente de correlação $(\mathbf{r})$, assimetria $\left(\mathbf{C}_{\mathbf{s}}\right)$, curtose $\left(\mathbf{C}_{\mathbf{r}}\right)$ e da estatística $(\mathbf{z})$, considerando que os desvios se distribuem normalmente, conforme as seguintes relações:

$$
\begin{aligned}
& \mathrm{d}_{\mathrm{me}}=\Sigma\left(A R M_{\mathrm{i} .0-}-\mathrm{ARM}_{\mathrm{i} . \mathrm{e}}\right) / \mathrm{n} \\
& \mathrm{d}_{\mathrm{re}}=\mathrm{d}_{\mathrm{me}} / \text { ARM }_{\mathrm{e} . \mathrm{m}} \\
& \sigma=\left[\sum\left(\mathrm{ARM}_{\mathrm{i} .0}-\mathrm{ARM}_{\mathrm{i} . \mathrm{e}}\right)^{2} / \mathrm{n}\right]^{0.5} \\
& r=\left[\Sigma\left(A_{R} M_{i \cdot e-}-A R M_{e . m}\right)\left(A R M_{i . o-} A R M_{0 . m}\right) \cdot n^{-1}\right] / \sigma_{e} \cdot \sigma_{0}
\end{aligned}
$$




$$
\begin{aligned}
& s d_{m e}=1 / n^{0,5}+\left(\left(\sum d_{i}{ }^{2}-\left(\sum d_{i}\right)^{2} \cdot 1 / n\right) / n\right)^{0,5} \\
& \left.z=d_{m e} d\left(\left(\sigma_{E}{ }^{2} \cdot \sigma_{o}{ }^{2}\right)^{0,5}\right) /(1 / n)^{2}\right)
\end{aligned}
$$

onde: ARM $_{\text {i.o e }} \mathbf{A R M}_{\mathrm{i} . \mathrm{e}}$ são os valores do armazenamentos medido e estimado, respectivamente; $\mathbf{n}$ é o número de medidas feitas; $\mathbf{A R M}$ e.m é o valor médio do armazenamento estimado; $\mathbf{A R M}_{\text {o.m }}$ é o armazenamento médio observado $\sigma_{e}$ é o desvio padrão do armazenamento estimado e $\sigma_{\circ}$ é o desvio padrão do armazenamento observado; $\mathbf{d}_{\mathbf{i}}$ é o desvio absoluto do dia $\mathbf{i}$. 


\section{RESULTADOS E DISCUSSÃO}

\subsection{Armazenamento da água no solo}

A umidade do solo determinada diariamente pela sonda de neutrons nos tubos de números 1 a 6 , entre 11/02 a 30/06/95, evidenciou um coeficiente de variação entre 10,36 e $17.84 \%$ para a profundidade de $20 \mathrm{~cm}$; entre 12,16 e $25,33 \%$ para a profundidade de $40 \mathrm{~cm}$; entre 3,91 e 10,59\% para a profundidade de $60 \mathrm{~cm}$; entre 5,18 e $9,34 \%$ para a profundidade de $80 \mathrm{~cm}$; e entre 4,27 e $11,03 \%$ para a profundidade de $100 \mathrm{~cm}$ (Quadro 1).

As leituras mostraram-se mais homogêneas para as profundidades além de $60 \mathrm{~cm}$, especialmente a partir de abril; isso se explica pelas trocas de massa e energia que ocorrem nas camadas mais superficiais do solo, alem do fato de que para maiores profundidades $(60$ a $100 \mathrm{~cm})$ o perfil apresenta uma certa homogeneização no que diz respeito às características físicas, aproximando também as curvas de calibração para esssas profundidade.

Considerando as datas constantes no Quadro 2, verifica-se que a variação do armazenamento guardou uma relação com as precipitações ocorridas de 11/02 a $30 / 6 / 95$ fevereiro $=38,1 \mathrm{~mm} ;$ março $=175,6 \mathrm{~mm} ;$ abril $=243,1 \mathrm{~mm} ;$ maio $=185,5$ $\mathrm{mm} ;$ e junho $=36,5 \mathrm{~mm})$ 
Quadro 1 - Medida da umidade do solo $\left(\mathrm{cm}^{3} . \mathrm{cm}^{-3}\right)$ e do coeficiente de variação da sonda de neutrons - Pentecoste-Ce .1995

\begin{tabular}{cccccccccccc}
\hline $\begin{array}{c}\text { Prof. } \\
\text { (cm) }\end{array}$ & \multicolumn{2}{c}{ Fevereiro } & \multicolumn{2}{c}{ Março } & \multicolumn{2}{c}{ Abril } & \multicolumn{2}{c}{ Maio } & & Junho \\
& Umid. & CV (\%) & Umid. & CV (\%) & Umid. & CV $(\%)$ & Umid. & CV $(\%)$ & Umid. & CV (\%) \\
& média & & média & & média & & média & & média & \\
20 & 0,082 & 10,99 & 0,100 & 10,36 & 0,175 & 16,51 & 0,216 & 12,67 & 0,143 & 17,84 \\
40 & 0,185 & 25,33 & 0,212 & 22,94 & 0,262 & 13,96 & 0,278 & 12,16 & 0,250 & 17,36 \\
60 & 0,232 & 10,59 & 0,240 & 10,85 & 0,306 & 4,02 & 0,322 & 3,91 & 0,299 & 5,60 \\
80 & 0,198 & 9,34 & 0,210 & 9,16 & 0,344 & 5,00 & 0,373 & 5,18 & 0,351 & 5,61 \\
100 & 0,177 & 11,03 & 0,176 & 10,62 & 0,305 & 5,51 & 0,338 & 4,27 & 0,338 & 4,95 \\
\hline
\end{tabular}

Quadro 2 - Armazenamento cumulativo (mm) d'água no solo - Período 11/02 a 30/06/95. Pentecoste-Ce.

\begin{tabular}{ccccccc}
\hline Datas & $\begin{array}{c}\left.\text { Chuva( }{ }^{*}\right) \\
(\mathrm{mm})\end{array}$ & $\begin{array}{c}0-20 \\
(\mathrm{~cm})\end{array}$ & $\begin{array}{c}0-40 \\
(\mathrm{~cm})\end{array}$ & $\begin{array}{c}0-60 \\
(\mathrm{~cm})\end{array}$ & $\begin{array}{c}0-80 \\
(\mathrm{~cm})\end{array}$ & $\begin{array}{c}0-100 \\
(\mathrm{~cm})\end{array}$ \\
$11 / 02$ & & 15,26 & 37,54 & 69,11 & 125,23 & 149,43 \\
$17 / 02$ & 11,6 & 15,32 & 37,78 & 69,57 & 125,11 & 149,75 \\
$28 / 02$ & 25,4 & 16,96 & 40,78 & 71,09 & 128,05 & 151,03 \\
$10 / 03$ & 11,8 & 15,30 & 38,41 & 72,20 & 126,51 & 152,67 \\
$20 / 03$ & 8,9 & 24,89 & 55,32 & 79,15 & 144,60 & 160,34 \\
$31 / 03$ & 154,9 & 28,17 & 62,86 & 91,22 & 169,66 & 195,31 \\
$10 / 04$ & 124,0 & 34,13 & 74,56 & 102,69 & 198,51 & 239,79 \\
$20 / 04$ & 70,5 & 40,27 & 85,51 & 108,11 & 212,75 & 248,78 \\
$30 / 04$ & 49,1 & 42,55 & 89,31 & 108,95 & 217,27 & 251,03 \\
$10 / 05$ & 78,7 & 38,65 & 82,47 & 106,37 & 210,18 & 248,91 \\
$20 / 05$ & 58,3 & 44,72 & 93,27 & 111,37 & 223,17 & 255,65 \\
$31 / 05$ & 48,5 & 41,70 & 88,04 & 109,69 & 218,39 & 254,62 \\
$10 / 06$ & 9,7 & 30,55 & 67,69 & 97,58 & 189,71 & 237,10 \\
$20 / 06$ & 7,0 & 23,13 & 54,07 & 89,10 & 169,52 & 221,32 \\
$30 / 06$ & 19,8 & 21,58 & 51,18 & 87,57 & 164,24 & 215,01 \\
\hline
\end{tabular}

$\left({ }^{\star}\right)$ - Altura de chuva ocorrida no intervalo entre a data do registro e a imediatamente anterior. 
Conforme mostra o Quadro 3, para todos os dias selecionados, o coeficiente de variação sempre foi inferior a $10,0 \%$ considerado razoável tendo em vista à variabilidade natural das características dos solos, embora REICHARDT \& TURATTI (1991), tenham obtido coeficientes menores que $3,0 \%$.

Comparando a variância devido a umidade e a variância devido ao método de integração, fica clara a pequena significância desta última, reforçando a afirmativa de que o processo de calibração é extremamente importante para minimizar os erros por ocasião das determinações de umidade com a sonda de neutrons. À medida que os armazenamentos aumentaram, diminuiram os coeficientes de variação das medidas evidenciando uma menor variabilidade da umidade do solo e na resposta da sonda, influenciada principalmente pela camada mais superficial. As medidas de umidade feitas pelo método de moderação de neutrons, foram obtidas a partir das seguintes curvas de calibração:

$$
\begin{array}{llr}
20 \mathrm{~cm}: & \Theta=0,03231695+0,6955398 . C R \\
& \left(r^{2}=0,887\right) & (F=563,4) \\
40 \mathrm{~cm}: & \Theta=0,03922129+0,6206527 . C R \\
& \left(r^{2}=0,828\right) & (F=314,0) \\
60 \mathrm{~cm}: & \Theta=0,038148220,6054525 . C R \\
& \left(r^{2}=0,856\right) & (F=334,0) \\
80 \mathrm{~cm}: & \Theta=-0,1057253+0.9958341 . C R \\
& \left(r^{2}=0,748\right) & (F=217,0) \\
100 \mathrm{~cm}: & \Theta=-0,1285449+0,9981952 . C R
\end{array}
$$




$$
\left(r^{2}=0,814\right) \quad(F=265,0)
$$

onde CR é a contagem relativa dos neutrons moderados.

Quadro 3 - Variâncias do armazenamento devido à umidade e ao método de integraçao das medidas da sonda - Pentecoste.Ce- 1995.

\begin{tabular}{ccccccc}
\hline DATAS & $\sigma^{2}(\Theta) \mathrm{cm}^{2}$ & $\sigma^{2}(\mathrm{l}) \mathrm{cm}^{2}$ & $\sigma^{2}(\mathrm{~T}) \mathrm{cm}^{2}$ & $\sigma(\mathrm{mm})$ & $\mathrm{A}(\mathrm{mm})$ & $\mathrm{CV}(\%)$ \\
\hline $15 / 02$ & 1,7414 & $6 \times 10^{-8}$ & 1,7414 & 13,2 & 150,41 & 8,774 \\
$28 / 02$ & 1,6432 & $8 \times 10^{-8}$ & 1,6432 & 12,82 & 150,84 & 8,498 \\
$15 / 03$ & 1,9823 & $2 \times 10^{-7}$ & 1,9823 & 14,08 & 155,37 & 9,062 \\
$31 / 03$ & 1,6022 & $4 \times 10^{-7}$ & 1,6022 & 12,66 & 195,31 & 6,481 \\
$15 / 04$ & 0,8530 & $5 \times 10^{-7}$ & 0,8530 & 9,236 & 244,85 & 3,772 \\
$30 / 04$ & 1,0144 & $3 \times 10^{-7}$ & 1,0144 & 10,07 & 251,03 & 4,012 \\
$15 / 05$ & 1,0856 & $4 \times 10^{-7}$ & 1,0856 & 10,42 & 25196 & 4.135 \\
$31 / 05$ & 1,2594 & $3 \times 10^{-7}$ & 1,2594 & 11,22 & 254,62 & 4,408 \\
$15 / 06$ & 1,1703 & $4 \times 10^{-7}$ & 1,1703 & 10,82 & 227,15 & 4,762 \\
$30 / 06$ & 2,0410 & $3 \times 10^{-7}$ & 2,0410 & 14,29 & 215,01 & 6,645 \\
\hline
\end{tabular}

Para as profundidades de 20,40 e $60 \mathrm{~cm}$, há uma certa proximidade nos valores dos coeficientes angular e linear das curvas de calibração, o mesmo ocorrendo para as profundidades de 80 e $100 \mathrm{~cm}$. A análise de variância das regressões para obtenção das curvas de calibração, através do coeficiente de determinação $\mathbf{r}^{2}$ e do teste $\mathbf{F}$, revelou significante influência do conteúdo de água do solo, no número de neutrons moderados.

O armazenamento da água no solo no período, até a profundidade de $100 \mathrm{~cm}$, apresentou um coeficiente de variação da ordem de 19,8\%, uma média de 211,66 mm e uma amplitude de 109 mm; este comportamento é explicável devido a sub- 
períodos com chuvas espaçadas e de baixa intensidade e a um intervalo com chuvas mais frequentes e mais fortes. O primeiro foi de 11/02 a 19/03 (37 dias), seguido de um intervalo chuvoso de 20/03 a 24/05 (66 dias) e finalmente um terceiro sub-período de 25/05 a 30/06, com a redução das precipitações (37 dias). O volume da precipitação pluviométrica total foi de $678,2 \mathrm{~mm}$, dos quais $84 \%$ ocorreu no período de $20 / 03$ a $24 / 05$, enquanto a evaporação correspondeu a $57,8 \%$ desse montante.

Analisando a variação da umidade no tempo, vê-se que partindo de condições iniciais de baixa umidade (11/02), à medida que novas precipitações ocorriam, todas as camadas aumentaram o conteúdo de água; entretanto, o coeficiente de variação da camada de 0 a $20 \mathrm{~cm}$ cresceu, enquanto para as demais camadas houve uma menor variabilidade da umidade no solo, quando o solo estava mais úmido; este fato pode ser explicado pela maior velocidade de extração de carga e recarga de água nas camadas superficiais (Figura 3). Enquanto na camada de 0 a $20 \mathrm{~cm}$, a variação da umidade entre o nivel mais baixo e o mais alto foi da ordem de $209,6 \% \quad\left(0.0763\right.$ a $\left.0,2362 \mathrm{~cm}^{3} \cdot \mathrm{cm}^{-3}\right)$, nas demais camadas a variação média NIELSEN (1980), citados por LIBARDI et alii (1996), as camadas de 0 a $20 \mathrm{~cm}$ e de 20 a $40 \mathrm{~cm}$, apresentaram uma variação média ( $12 \%<C V \%<60 \%)$ e além de $40 \mathrm{~cm}$, baixa variação $(\mathrm{CV} \%<12 \%)$.

Observando-se o armazenamento ao longo do periodo experimental, nota-se que a diminuição da umidade a partir da saturação das camadas abaixo de $40 \mathrm{~cm}$, 


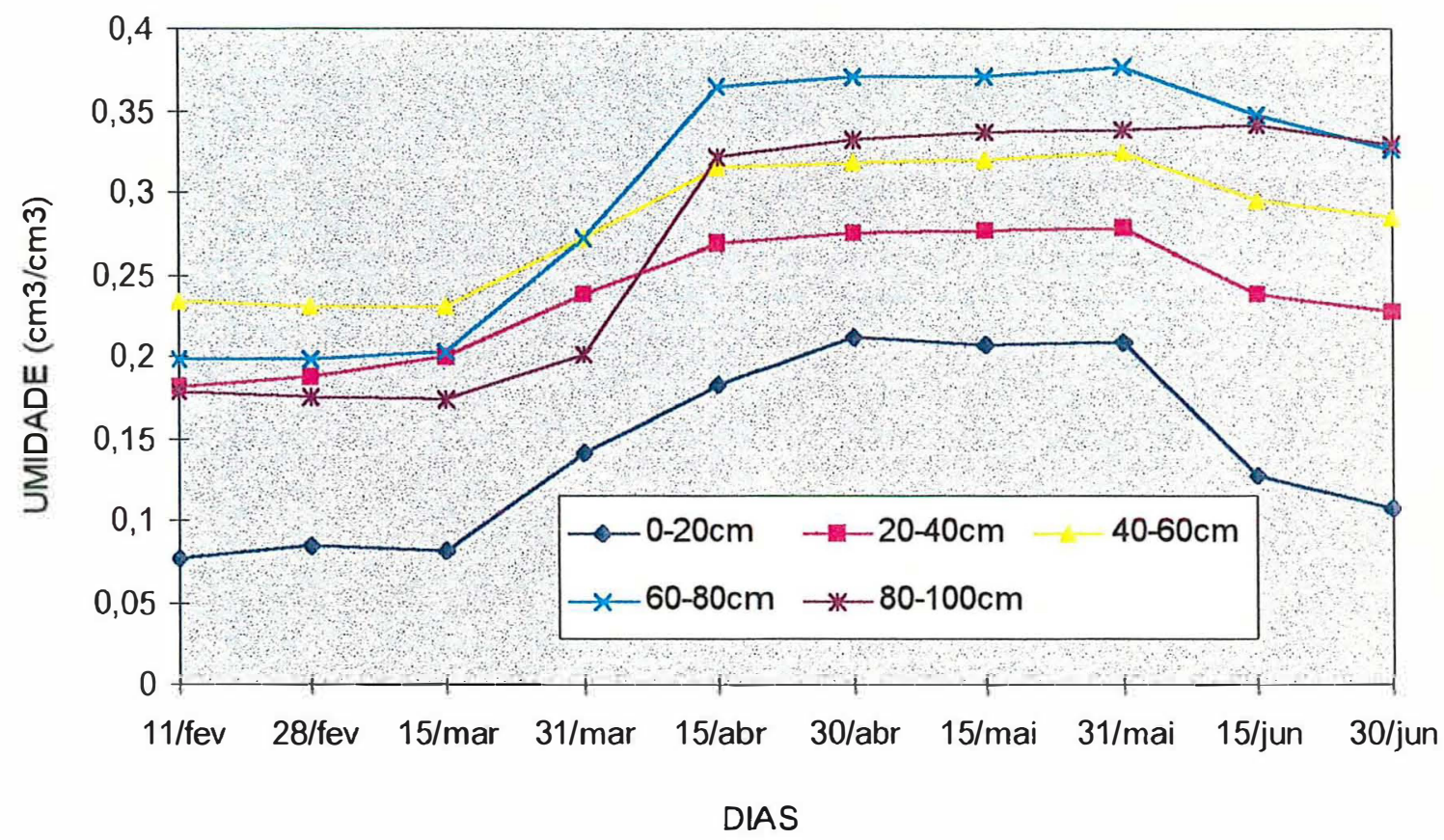

Figura 3. Conteúdo de água no solo e precipitação pluvial no periodo de 11/02 a 30/06/95, Pentecoste-Ce. 1995.

ocorre bem mais lentamente do que nas camadas superiores, sugerindo a existência de uma camada de retardamento a essa profundidade. Isso está de acôrdo tambem com a variação da textura segundo a profundidade (Quadro 4); entre 40 e $60 \mathrm{~cm}$ ocorre o maior teor de argila e entre 40 e $80 \mathrm{~cm}$ a densidade global tem os máximos valores no perfil. 
Quadro 4 - Características físicas do solo - Pentecoste.Ce

\begin{tabular}{ccccccccc}
\hline Horizonte & $\begin{array}{c}\text { Camada. } \\
(\mathrm{cm})\end{array}$ & $\begin{array}{c}\text { Areia } \\
\text { grossa }\end{array}$ & $\begin{array}{c}\text { Areia } \\
\text { fina }\end{array}$ & $\begin{array}{c}\text { Silte } \\
\%\end{array}$ & $\begin{array}{c}\text { Argila } \\
\%\end{array}$ & $\begin{array}{c}\text { Densid. } \\
\%\end{array}$ & $\begin{array}{c}\text { Umid. } \\
\text { global }\end{array}$ & $\begin{array}{c}\text { Umid. } \\
\end{array}$ \\
\hline $\mathrm{A}_{\mathrm{p}}$ & $0-20$ & 40 & 42 & 7 & 11 & 1.51 & 9.1 & $15 \mathrm{~atm} \%$ \\
$\mathrm{~A}_{\mathrm{p}}$ & $20-40$ & 34 & 23 & 13 & 30 & 1.55 & 19.6 & 10.6 \\
$\mathrm{~B}_{\mathrm{t}}$ & $40-60$ & 26 & 16 & 18 & 40 & 1.63 & 23.7 & 12.6 \\
$\mathrm{~B}_{\mathrm{t}}$ & $60-80$ & 31 & 20 & 18 & 31 & 1.67 & 21.2 & 12.6 \\
$\mathrm{~B}_{\mathrm{t}}$ & $80-100$ & 33 & 18 & 19 & 30 & 1.58 & 20.9 & 10.8 \\
\hline
\end{tabular}

\subsection{Função de infiltração}

Para o cálculo do volume infiltrado no solo, o MUSAG baseia-se no modeo de infiltração de Holtan, geralmente apresentado de duas formas:

$$
\begin{aligned}
& i=a(S-I)^{n}+i_{f} \\
& i-D\left[(S-I) / \Theta_{0}\right]^{n}
\end{aligned}
$$

onde $\mathbf{i}$ é a capacidade de infiltração do solo, $\mathbf{S}$ é o potencial de armazenagem de água acima da camada impermeável, I é a infiltração acumulada, D é o máximo aumento potencial na capacidade de infiltração e $\Theta_{0}$ é a umidade de saturação considerando a profundidade da camada de impedimento e $\mathbf{n}$ é a declividade da curva de infiltração.

O MUSAG estabelece que a velocidade de infiltração assume o valor de if quando o solo encontra-se saturado (ANDRADE, 1995). Isso implica que na 
equação (23) $\left(\mathbf{i}_{0}-\mathbf{i}_{\mathbf{f}}\right)[(\mathbf{C C}-\Theta) / C C]^{\alpha}$ seja zero; como $\mathbf{i}_{0}$ e $\mathbf{i}_{\mathbf{f}}$ são positivos, a única condição é que $[(\mathbf{C C}-\Theta) / C C]^{\alpha}$ seja zero; sendo $\alpha \neq 0$, conclui-se que (CC $\Theta) / C C=0$, ou seja, $C C-\Theta=0$ e finalmente $C C=\Theta$.

No modelo estudado, CC é conceituado como sendo a capacidade máxima de retenção da água não gravitacional na parcela contida no primeiro metro de profundidade, que na verdade é o conceito de "capacidade de campo". Quando $\Theta=C C$, há no solo um espaço poroso livre de água, encontrando-se insaturado, contrariando a condição assumida de $\mathbf{i}_{\mathbf{i}}=\mathbf{i}_{\mathbf{f}}$.

Comparando a função de infiltração do MUSAG com o modelo de Holtan, nota-se que $\left(\mathbf{i}_{\mathrm{o}}-\mathbf{i}_{\mathrm{f}}\right)$ é equivalente a $\mathbf{D} ; \mathrm{e}(\mathbf{C C}-\Theta)$ é semelhante a $(\mathbf{S}-\mathbf{I})$. Devido a isso, no ajustamento da função de infiltração do MUSAG, foi utilizado o parâmetro "umidade de saturação" $\left(\Theta_{0}\right)$ ao invés de capacidade de campo (CC).

A utilização da função de infiltração do MUSAG, dada a sua rotina de cálculo, necessita, a rigor, do registro da duração da chuva a pequenos intervalos de tempo durante o período, para se alcançar um cálculo mais preciso do escoamento superficial.

Como no procedimento de cálculo do volume infiltrado a precipitação foi considerada distribuida uniformemente ao longo dia, os valores de $\mathbf{i}_{0}$ e $\mathbf{i}_{f}$ assumem uma forma integralizada (valor médio) para o dia, visto que $\mathbf{i}_{0}$ e $\mathbf{i}_{f}$ variam ao longo do período em que ocorre a precipitação. Usando essa linha de raciocínio, após a realização de 18 testes de infiltração, em cada equação ajustada segundo o modelo de Kostiakov, foi calculada a lâmina infiltrada para $t=1,0$ dia, partindo-se de uma 
condição de umidade mais baixa possível. A capacidade máxima de infiltração do solo estudado, tomada como média, alcançou o valor de $1.128,2 \mathrm{~mm} / \mathrm{dia}$, equivalente a $1,34 \times 10^{-3} \mathrm{~cm} / \mathrm{s}$, próximo a adotada por ISRAELSEN \& HANSEN (1967) para solos arenosos $\left(1,4 \times 10^{-3} \mathrm{~cm} / \mathrm{s}\right)$.

As equações ajustadas de $\mathbf{I}(\mathrm{cm})$ como função de $\mathbf{t}(\mathrm{min})$, na área de influência de cada tubo foram:

TUBO 1: $I=1,034 \cdot t^{0,6629}$

$$
(r=0,996)
$$

TUBO 2: $1=0,6877 \cdot t^{0,7012}$

$$
(r=0,998)
$$

TUBO 3: $1=0,3977 \cdot \mathrm{t}^{0,7677}$

$$
(r=0,999)
$$

TUBO 5: $I=0,5356 \cdot t^{0,7275}$

$$
(r=0,92)
$$

TUBO $6: I=0,8600 \cdot t^{0,6814}$

$$
(r=0,990)
$$

TUBO $7: 1=0,4376 \cdot t^{0,7492}$

$$
(r=0,998)
$$


As divergências encontradas entre os valores de $i_{0}$ e entre os valores de $\mathbf{b}$ para os diversos tubos, em parte, deve-se aos diferentes intervalos de tempo utilizados nos testes; entretanto, a amplitude de b foi de $13,0 \%$ e a amplitude de $\mathbf{i}_{0}$ foi de $26,24 \%$, valores relativamente baixos considerando a alta variabilidade espacial das características físicas encontrada na maioria dos solos.

O parâmetro i para tempos curtos pode ser associado à capacidade de absorção de água pelo solo; no caso, dada a natureza arenosa da camada superficial, $I_{0}$ mostrou-se bastante elevado. Tomando como exemplo a equação de infiltração na área de influência do Tubo 2, cujo valor de $i_{0}=1127,3$ $\mathrm{mm} /$ dia é o mais próximo da média, verifica-se que para uma chuva de $60 \mathrm{~mm} / \mathrm{h}$, estando o solo na sua condição de mais baixa umidade $\left(\Theta=0,0753 \mathrm{~cm}^{3} \cdot \mathrm{cm}^{-3}\right)$ em 11/2, o escoamento superficial ocorrerá após 3 horas de duração (Figura 3).

No decorrer do experimento, o primeiro evento de escoamento superficial ocorreu em 27/03, quando houve uma precipitação de 76,4 mm neste dia; a umidade do solo na camada de 0 a $20 \mathrm{~cm}$ era de $0,1517 \mathrm{~cm}^{3} \cdot \mathrm{cm}^{-3}, 13$ vezes maior que no dia 11/02, corroborando a influência do conteúdo de água inicial na capacidade de infiltração dos solos.

Os valores de b ajustados variam de 0,66 a 0,75, coerentes com a granulometria do solo estudado, comparados com valores encontrados por outros pesquisadores. HARTLEY (1992), cita uma revisão dos trabalhos de determinação de b, em 29 séries do parâmetro; em 27 destas séries, encontraram-se valores entre 0,3 e0,7 e destes, 21 ficam entre 0,55 e 0,70 Êsse estudo revelou que para 
valores de $\mathbf{b} \geq \mathbf{0 , 5}$, a substituição da equação empírica de Kostiakov pela equação contendo o termo C.t, produziu diferenças negligiveis.

Os testes de infiltração para se identificar a relação $i(\Theta)$ segundo a equação (23), foram realizados na área de influência de todos os tubos, tendo-se eliminado uma série de dados devido a um êrro experimental. Os valores de $\alpha$ variaram de 0,7789 a 2,1343 , sendo que $71,4 \%$ ficaram entre 1,0 e 2,0 , obtendo-se um valor médio de $\alpha=1,4726$; este critério também foi adotado por HOLTAN et alii (1967) para vários tipos de solos, encontrando 1,387. HOLTAN \& CREITZ (1969) citados por SKAGGS et alii (1967) sugerem que $\alpha$ pode ser tomado como uma constante igual a 1,4 para todos os tipos de solos; assim o valor de $\alpha$ encontrado no presente trabalho está de acôrdo com a maioria encontrada em outros estudos.

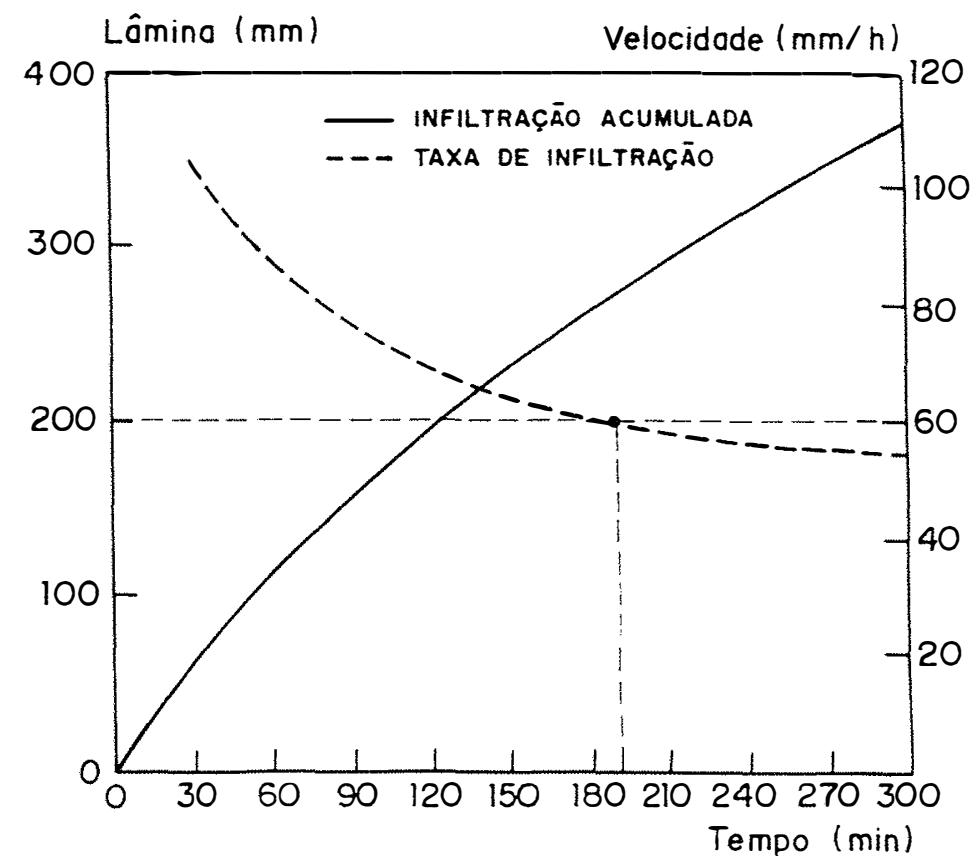

Figura 4. Velocidade de infiltração e infiltração acumulada da água no solo (Tubo 2), Pentecoste-Ce. 
Comparando-se as diversas relações $i(\Theta)$ obtidas nas diferentes áreas de influência entre os tubos, verifica-se que a velocidade de infiltração em condições mais úmidas situou-se entre 0,10 e $0,15 \mathrm{~cm} / \mathrm{min}$; já para as condições de baixas umidades a amplitude foi maior $(0,70$ a $1,35 \mathrm{~cm} / \mathrm{min})$, evidenciando que a influência do conteúdo inicial de água na infiltração, diminui à medida que o solo ganha umidade.

A função de infiltração ajustada segundo a equação (23) foi:

$$
\mathrm{i}=17,49+(1128,2-17,49)\left[\left(\Theta_{0}-\Theta\right) / \Theta_{0}\right]^{1,4726}
$$

sendo $\mathbf{i}$ dada em mm/dia e $\Theta_{0}$ a umidade de saturação correspondente a cada profundidade considerada, dada em $\mathrm{mm}$. O valor de $3,48 \mathrm{~mm} /$ dia para $\mathrm{I}_{\mathbf{f}}$ será discutido mais adiante no tópico referente à percolação profunda.

Aplicando a equação para diversos níveis de $\Theta$, verifica-se que, quando a umidade do solo fica reduzida a $65 \%$ da umidade de saturação, a taxa de variação de $\mathbf{i}$ é praticamente igual para todas as profundidades.

O solo estudado apresenta uma distribuição de tamanho de poros, de tal forma que um grande percentual da porosidade efetiva encontra-se no horizonte Ap, indicando o limite superior do horizonte que controla a infiltração, isto é, a camada de 40 até $100 \mathrm{~cm}$, limitou a taxa de infiltração. Isso explica o surgimento de potenciais positivos observados nos meses de abril e maio, épocas de maiores precipitações pluviométricas. Embora crescendo com aiores volumes de chuva, as pressões positivas não influenciam na taxa de infiltração (COLMAN \& BODMAN, 1944). 


\subsection{Função de percolação}

A função de percolação do MUSAG é dada pela equação (24). Os fluxos de drenagem profunda foram calculados diariamente através da equação da equação de Darcy para o período 11/2 a 30/6/95.

A condutividade hidráulica, em $\mathrm{cm} / \mathrm{h}$, obtida para as cinco profundidades, resultou nas seguintes equações:

$$
\begin{aligned}
& 20 \mathrm{~cm}: \mathrm{K}(\Theta)=1,096 \cdot e^{55,259(\Theta-0,2437)} \\
& 40 \mathrm{~cm}: \mathrm{K}(\Theta)=0,508 \cdot e^{117,79(\Theta-0,2818)} \\
& 60 \mathrm{~cm}: \mathrm{K}(\Theta)=0,471 \cdot e^{208,41(\Theta-0,3258)} \\
& 80 \mathrm{~cm}: \mathrm{K}(\Theta)=2,030 \cdot e^{99,55(\Theta-0,3795)} \\
& 100 \mathrm{~cm}: \mathrm{K}(\Theta)=2,330 \cdot e^{115,79(\Theta-0,3450)}
\end{aligned}
$$

Analisando as Figuras 5, 6, 7, 8, 9, 10 e 11, verifica-se que a variação da umidade com o tempo, apresenta para a camada de 0 a $20 \mathrm{~cm}$, um padrão bastante diferente das demais camadas( especialmente para os tubos 1, 2, 3 e 5), as quais mostram entre si um comportamento semelhante. A redução rápida da umidade na camada de 0 a $20 \mathrm{~cm}$, tem uma relação muito estreita com a distribuição de tamanho dos poros, caracterizada por uma maior macroporosidade nessa camada, associada ao aumento do teor de argila e uma redução no teor de areia para as camadas mais profundas. Resultados semelhantes foram também encontrados por MALLANTS et all. (1996). 


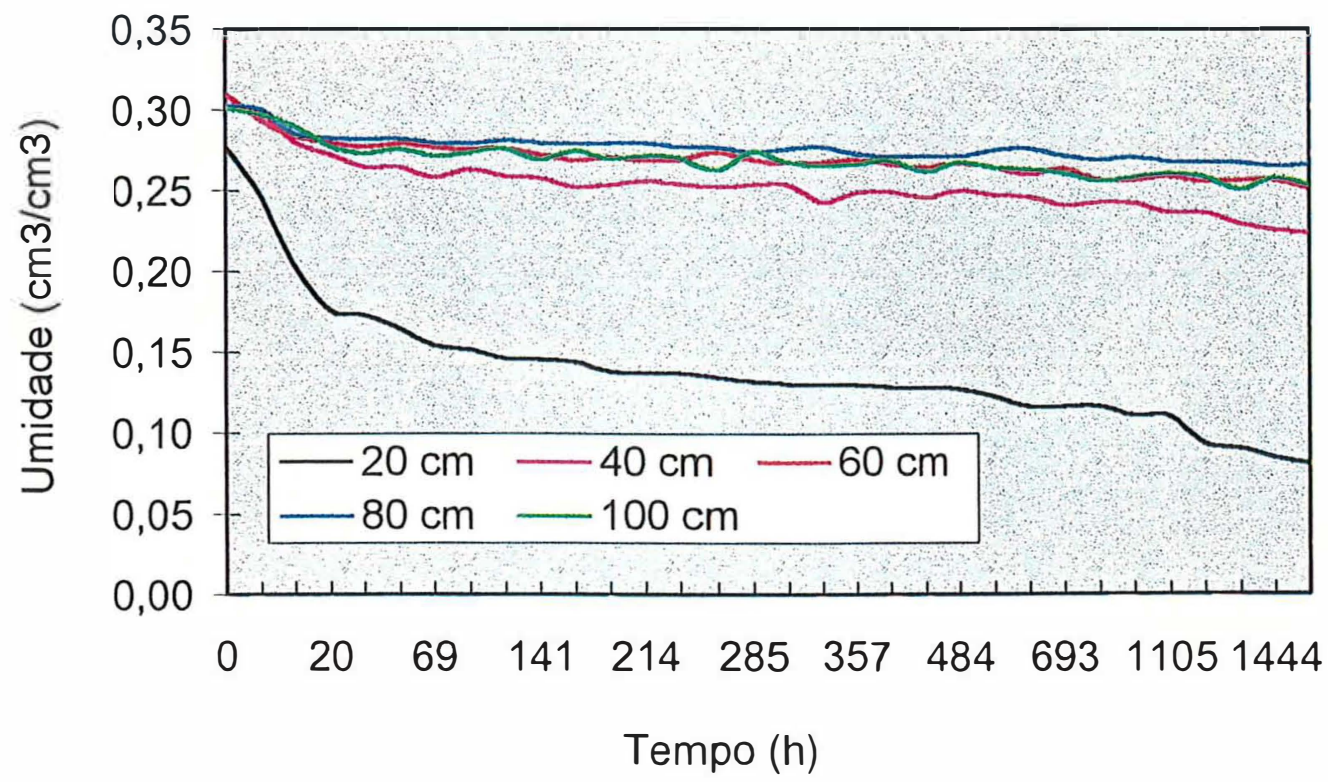

Figura 5. Redistribuição da água no solo (Tubo 1), Pentecoste-Ce

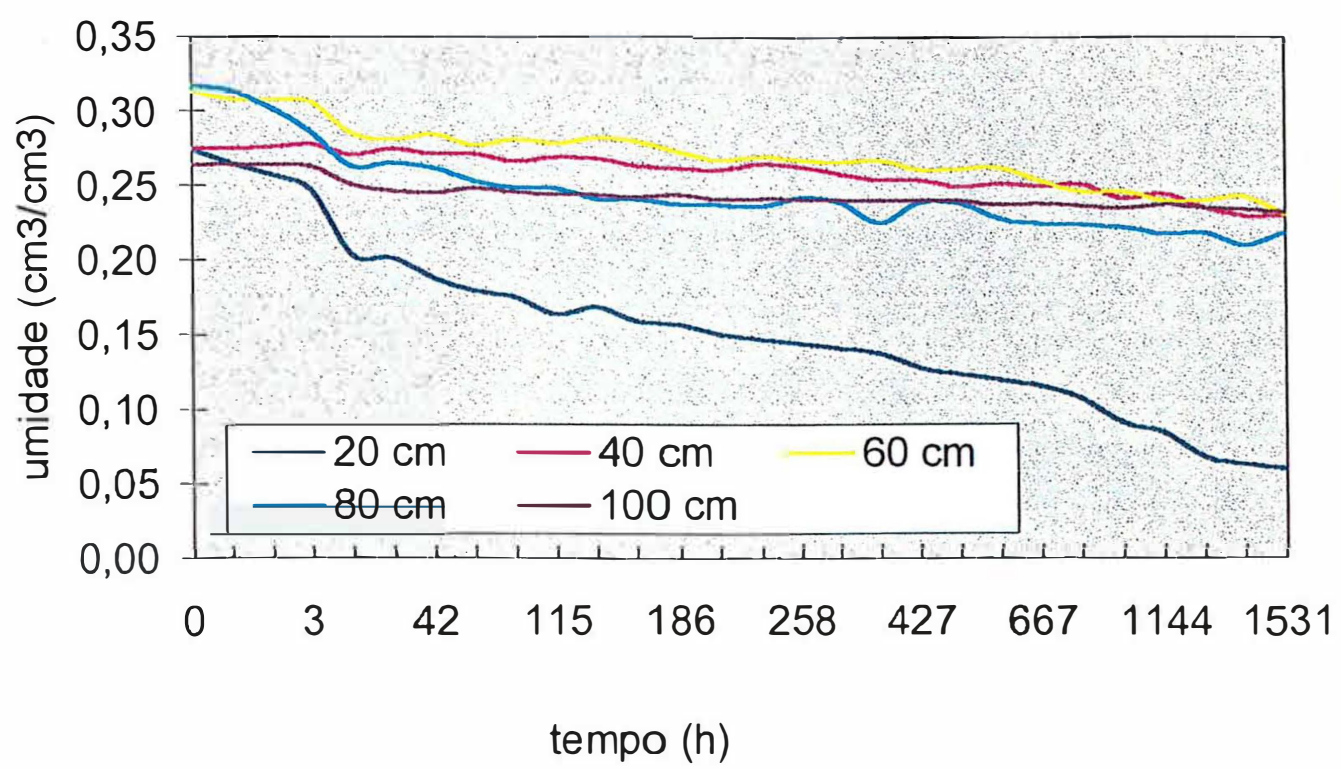

Figura 6. Redistribuição da água no solo (Tubo 2), Pentecoste-Ce 


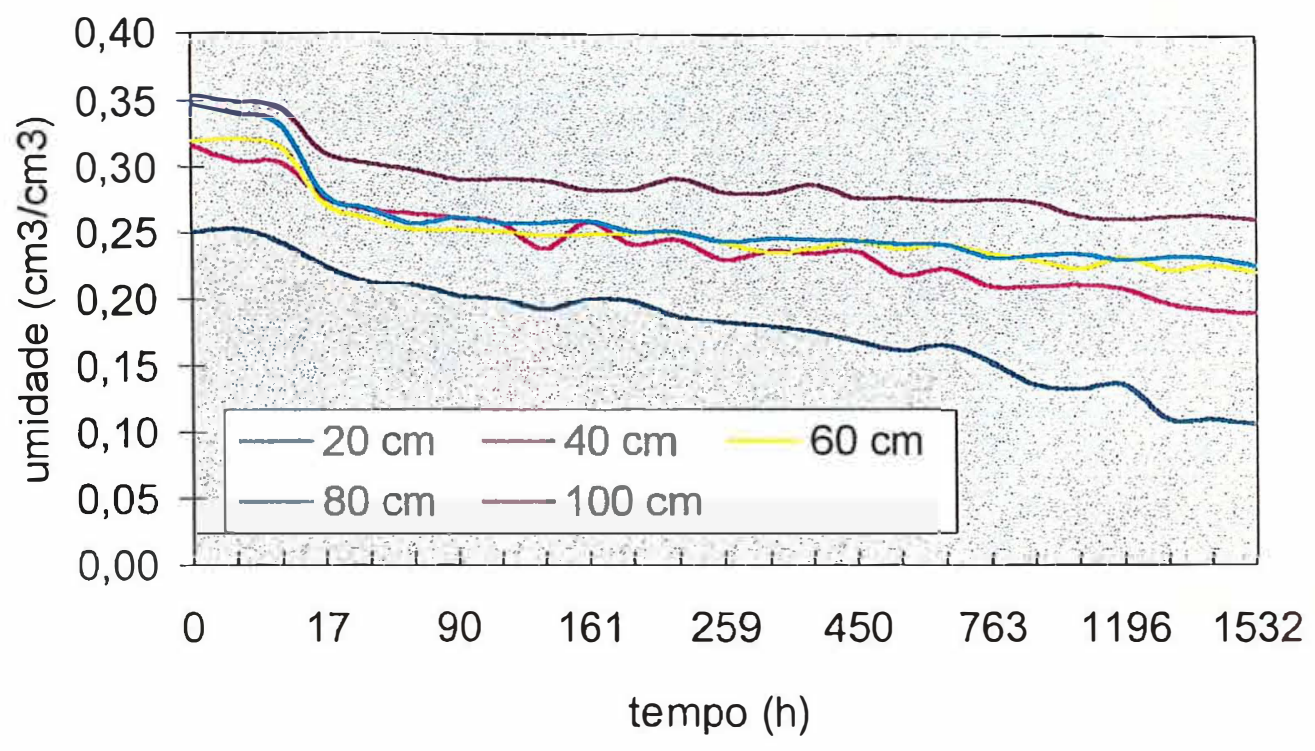

Figura 7. Redistribuição da água no solo (Tubo 3), Pentecoste-Ce

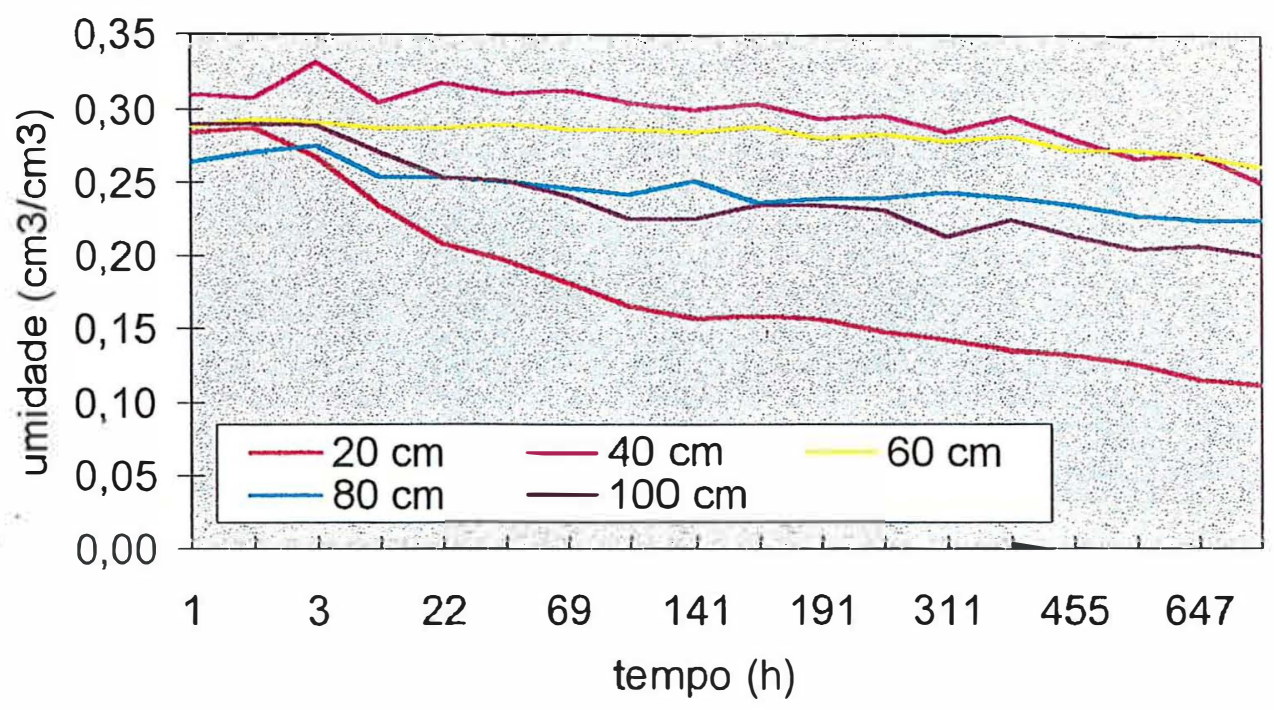

Figura 8. Redistribuição da água no solo (Tubo 5), Pentecoste-Ce 


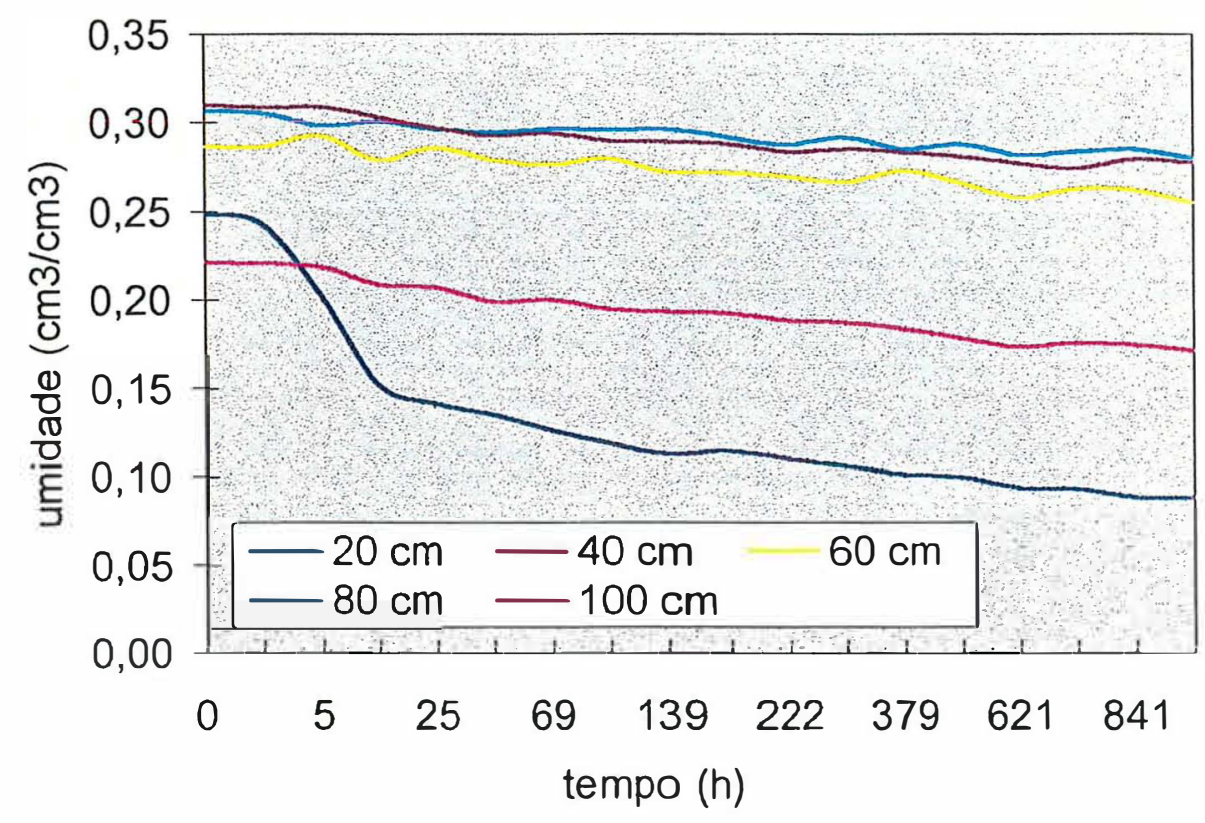

Figura 9. Redistribuição da água no solo (Tubo 6), Pentecoste-Ce

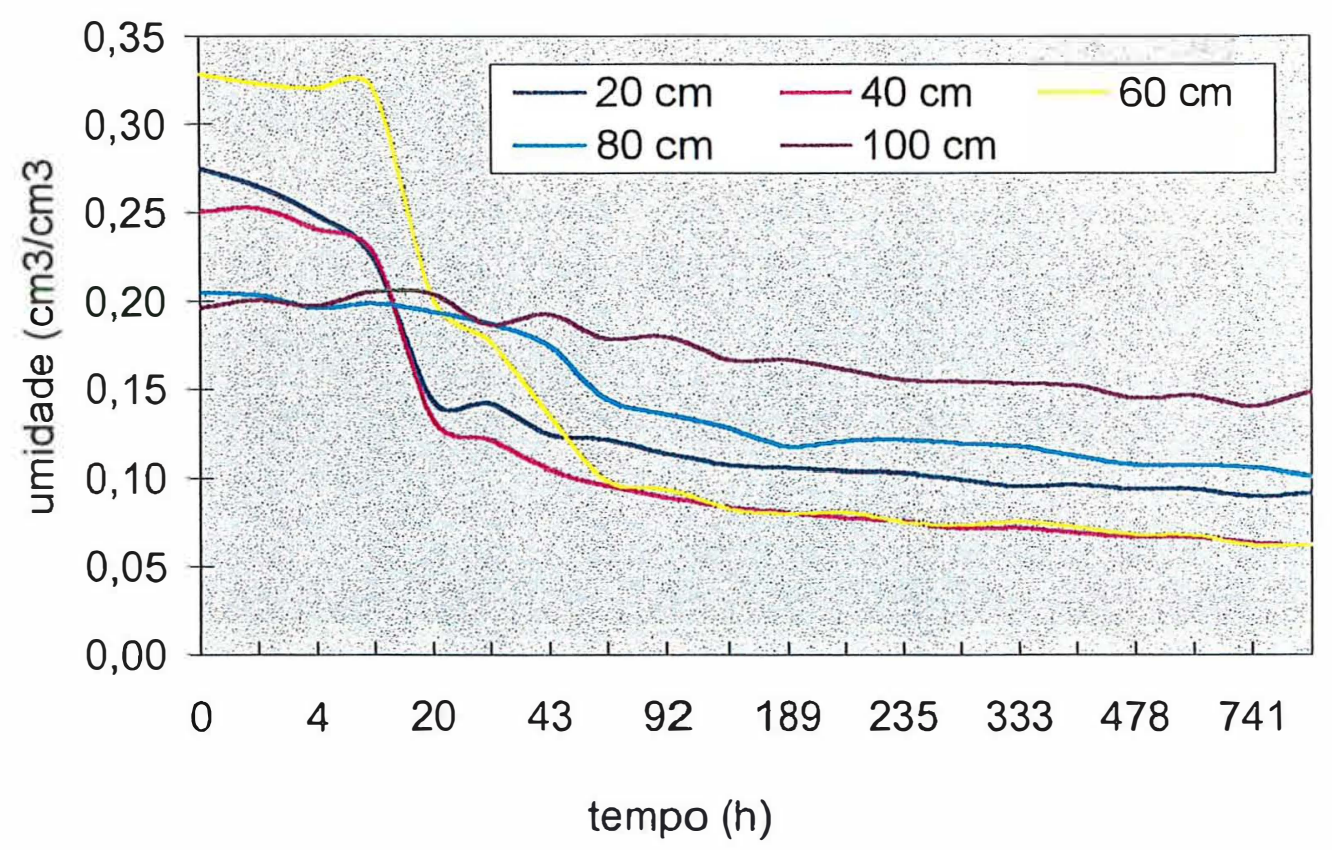

Figura 10. Redistribuição da água no solo (Tubo 8), Pentecoste-Ce 


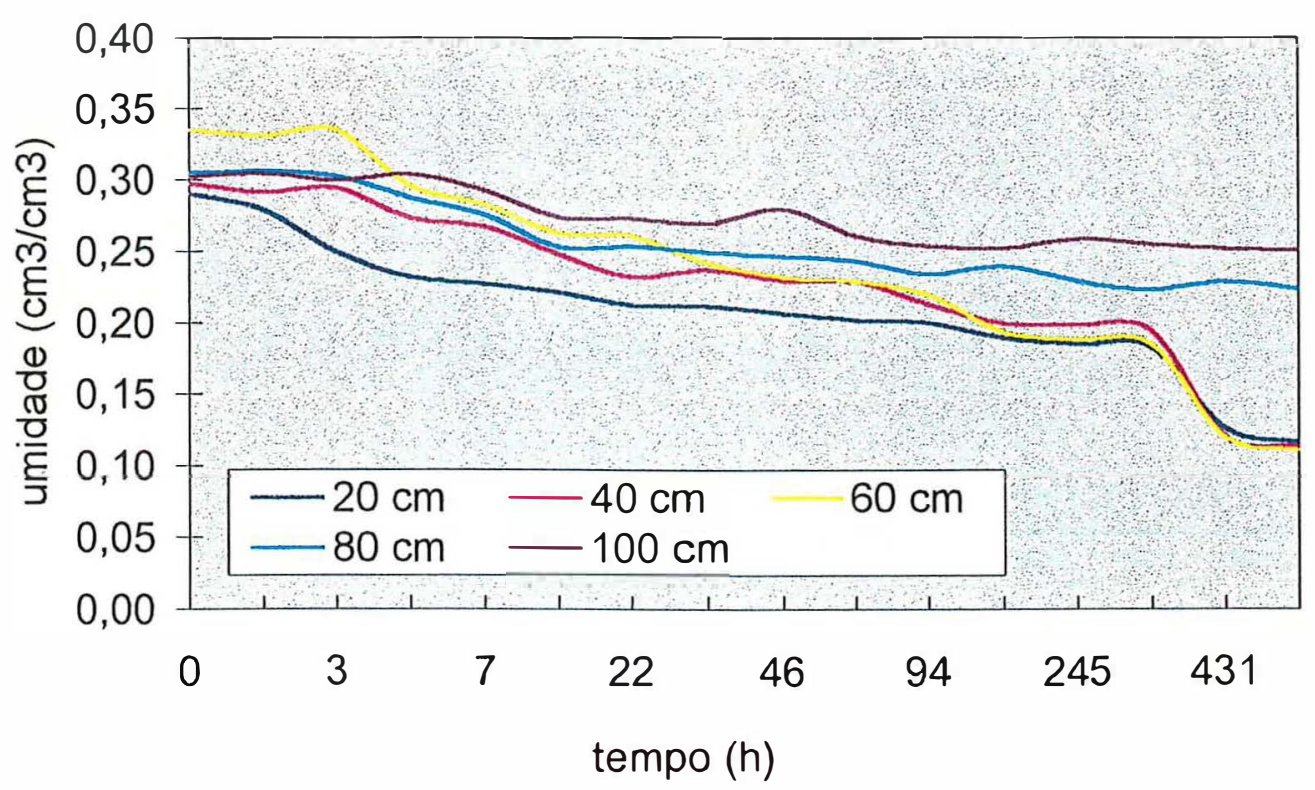

Figura 11. Redistribuição da água no solo (Tubo 9), Pentecoste-Ce

Quanto aos tubos 8 e 9, a diferença na redistribuição da água em relação aos demais, é porque esses tubos foram colocados em pontos que coincidiram com o leito de um pequeno curso d'água, que se forma durante a época das chuvas; nesses dois locais, a composição granulométrica do solo na camada de 0 a $100 \mathrm{~cm}$ apresenta um proporção da ordem de $48 \%$ para areia grossa e $26 \%$ para areia fina, enquanto a média do restante da área, foi de $33 \%$ e $24 \%$, respectivamente, explicando a semelhança na redistribuição da água para todas as camadas, na área de influência desses tubos, os quais não foram considerados no cálculo da condutividade hidráulica.

De 0 a $60 \mathrm{~cm}$, observa-se uma redução na condutividade hidráulica saturada explicada pela camada de impedimento existente entre as profundidades de 40 e 60 
$\mathrm{cm}$, também coincidente com o limite inferior do horizonte $A_{p}$. A condutividade hidráulica das camadas de 40 a $100 \mathrm{~cm}$, é praticamente desprezível quando a umidade do solo se reduz a menos de $85 \%$ da umidade de saturação, enquanto para a profundidade de $20 \mathrm{~cm}$, esse percentual cai para $66 \%$ (Figura 12). Em conseqüência, a percolação profunda a partir de $40 \mathrm{~cm}$ é desprezível até a umidade atingir valores próximos de $0,25 \mathrm{~cm}^{3} / \mathrm{cm}^{3}$. De acordo com O'NEAL (1952) e com os critérios adotados pelo Serviço e Conservação de Solo dos Estados Unidos da América, o solo estudado apresenta uma permeabilidade variando de lenta a moderadamente lenta.

O monitoramento dos gradientes de potencial hidráulico $(\partial \psi / \partial z)$ ao longo do período experimental, nas profundidades consideradas, mostram que a partir de 40 cm , $\partial \psi / \partial z$ reduziu-se drasticamente no início das chuvas mais fortes (26/03), até alcançar valores praticamente nulos, mais ou menos na mesma data (20/04 para 40 $\mathrm{cm}$; 06/04 para $60 \mathrm{~cm}$; 08/04 para 80 e $100 \mathrm{~cm}$ ), até quase o final do período (Quadro 5). No período de gradiente nulo, o solo manteve-se com uma umidade muito próxima a saturação; os potenciais de pressão assumiram valores positivos com gradientes aproximadamente unitários, neutralizados pelo gradiente gravitacional negativo, provocando a ausência de fluxos verticais. 


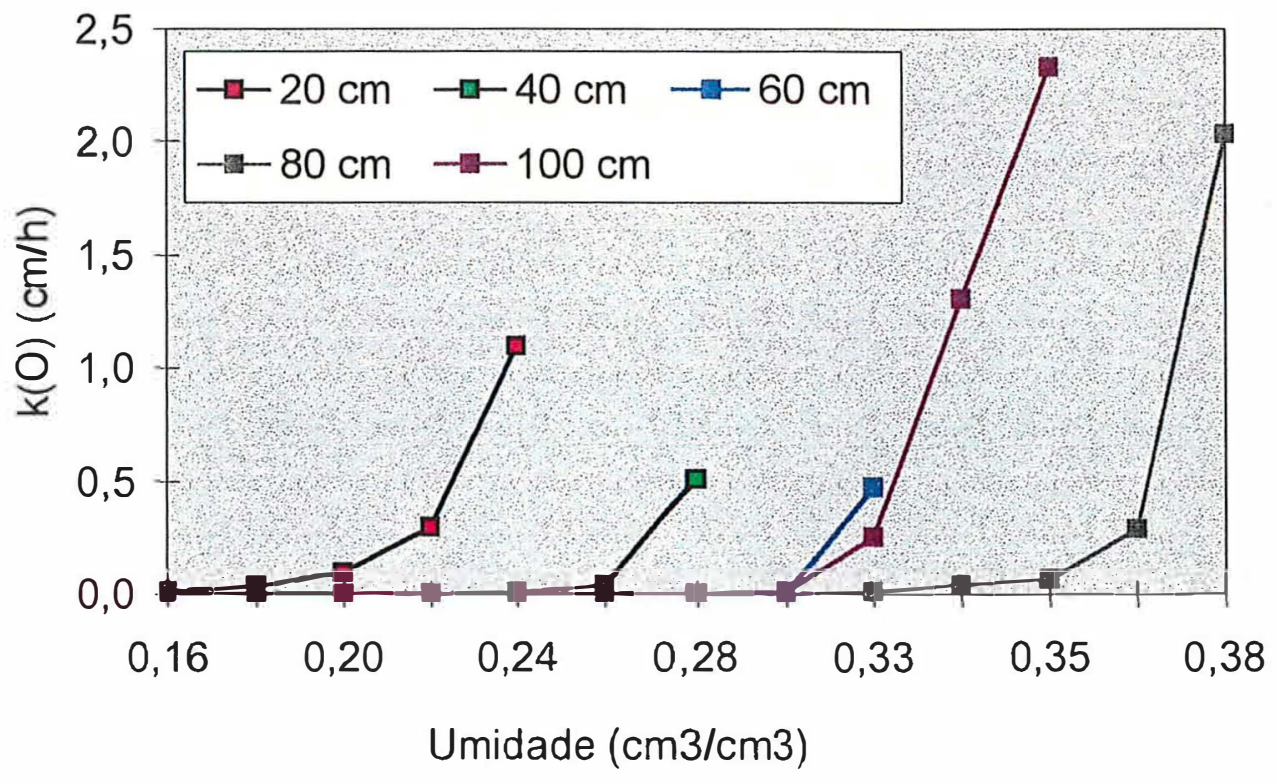

Figura 12. Condutividade hidráulica como função da umidade.

Quadro 5 - Gradientes de potencial hidráulico - Pentecoste-Ce

\begin{tabular}{rrrrrr} 
Datas & $10-30 \mathrm{~cm}$ & $30-50 \mathrm{~cm}$ & $50-70 \mathrm{~cm}$ & $70-90 \mathrm{~cm}$ & $90-110 \mathrm{~cm}$ \\
\hline $11 / 02$ & 1,60 & 6,09 & 0,43 & 0,89 & 4,99 \\
$17 / 02$ & 0,85 & 8,88 & 2,30 & $-1,67$ & $-1,18$ \\
$28 / 02$ & 3,83 & 10,43 & $-3,18$ & 2,12 & 2,50 \\
$10 / 03$ & 1,13 & 6,68 & $-1,72$ & 2,87 & 2,53 \\
$20 / 03$ & 13,76 & 6,02 & $-7,79$ & 7,69 & 3,16 \\
$31 / 03$ & 0,23 & 0,74 & 1,46 & 5,17 & 6,59 \\
$10 / 04$ & 0,11 & 0,21 & 0,00 & $-0,05$ & 0,02 \\
$20 / 04$ & 0,06 & 0,11 & 0,00 & $-0,02$ & 0,03 \\
$30 / 04$ & $-0,04$ & 0,19 & $-0,13$ & $-0,06$ & 0,12 \\
$10 / 05$ & $-0,05$ & 0,02 & 0,00 & $-0,08$ & $-0,02$ \\
$20 / 05$ & $-0,33$ & 0,17 & $-0,20$ & 0,05 & 0,01 \\
$31 / 05$ & 0,07 & 0,04 & 0,00 & 0,04 & 0,00 \\
$10 / 06$ & $-0,30$ & $-0,08$ & 0,00 & 0,03 & $-0,01$ \\
$20 / 06$ & $-1,32$ & $-0,34$ & 0,00 & 0,02 & 0,00 \\
$30 / 06$ & $-1,11$ & $-0,40$ & 0,21 & 0,02 & 0,00
\end{tabular}


As equações de percolação ajustadas foram:

$$
\begin{aligned}
& 20 \mathrm{~cm}: \mathrm{q}=17,488(\Theta / 0,2437)^{3,3} \\
& 40 \mathrm{~cm}: \mathrm{q}=11,703(\Theta / 0,2811)^{16,9} \\
& 60 \mathrm{~cm}: \mathrm{q}=27,268(\Theta / 0,3258)^{52,6} \\
& 80 \mathrm{~cm}: \mathrm{q}=62,517(\Theta / 0,3795)^{22,6} \\
& 100 \mathrm{~cm}: \mathrm{q}=43,680(\Theta / 0,3480)^{24,1}
\end{aligned}
$$

Os valores elevados de $\beta$ nas equações (66) a (70), significam uma grande sensibilidade na variação de q quando $\Theta$ varia, isto é, para pequenas mudanças na relação $\Theta / \Theta_{0}$, observa-se grandes variações nos valores de $q$; na camada de 0 a 20 cm se houver uma queda de $20 \%$ na umidade em relação a saturação. $p$ valor da percolação se reduz em 52\%; para as demais camadas a redução é maior que $96 \%$.

O coeficiente $\beta$ pode ser associado à porosidade do solo para uma mesma camada, dando lugar a um rápido esvaziamento dos mesmos, tornando a condutividade hidráulica praticamente nula; isso explica os baixos valores de if obtidos na equação de regressão de q versus $\Theta$.

\subsection{Função de evaporação}

As medidas feitas diariamente no Tanque Classe $A(E T)$ instalado na área experimental, foram corrigidas pelo coeficiente do tanque $\left(k_{p}\right)$, obtendo-se uma evaporação potencial média de $3,67 \mathrm{~mm} / \mathrm{dia}$, ao longo dos 5 (cinco) meses de levantamento dos dados. As médias mensais de ET variaram de 2,33 a 4,78 mm/dia. A computação dos dados de evaporação do tanque em base mensal é mais 
apropriada para o cálculo da evapotranspiração potencial porque as diferenças por erros de leitura, positivas ou negativas são compensadas (CHIEW \& McMAHON, 1992).

A evaporação acumulada do tanque apresentou valores mínimos no mês de abril e maio (2,33 e 3,40 mm/dia, respectivamente), devido à redução da irradiância global, do deficit de saturação do ar e em conseqûencia, dos gradientes de concentração de vapor d'água entre o ar e a superfície evaporante.

Considerando que o vento não atingiu em nenhum dia a velocidade de 175 $\mathrm{km} / \mathrm{dia}$, que a bordadura adotada foi de $100 \mathrm{~m}$ e a umidade relativa sempre ficou entre 40 e $70 \%$, o coeficiente do tanque utilizado para todo período foi de 0,8 .

O cálculo da evaporação foi realizado para 63 dias sem chuva, pelo balanço hídrico.Apesar do método apresentar algumas dificuldades, tem sido largamente usado por muitos pesquisadores (SHARMA, 1985; VILLAGRA et alii,1995; ZAYANI, 1996).

Como nesse período (63 dias) não houve precipitação pluviométrica nem escoamento superficial e a influência da percolação profunda foi muito pequena, os erros na determinação de EV foram significativamente reduzidos, ficando restritos praticamente à medida da variação do armazenamento, cujas determinações sendo diárias contribuem ainda mais para minimizar os erros decorrentes. Quando a EV é baixa, essas medidas podem ser feitas em bases mensais (SHARMA, 1985). 
A evaporação calculada apresentou valores muito baixos nos períodos de baixa precipitação, apesar da alta disponibilidade de energia, confirmando a influência do conteúdo de água na intensidade do fluxo.

A função de evaporação adotada pelo MUSAG representada pela equação (25) pode ser reescrita na seguinte forma:

$$
E V=\left(E V P / K^{r}\right)\left(\Theta / \Theta_{0}\right)^{\gamma}
$$

A expressão $\ln \left(E T P / K^{\gamma}\right)$ e $\gamma$ representam o intercepto e a inclinação da curva:

$$
\ln E V=\ln \left(E T P / K^{\gamma}\right)+\gamma \cdot \ln \left(\Theta / \Theta_{0}\right)
$$

Plotando-se um gráfico de $\ln (\mathrm{EV}) \times \ln \left(\Theta / \Theta_{0}\right)$ determina-se os parâmetros $\mathrm{k}$ e $\gamma$ para cada camada, tendo sido obtidas as expressões:

$$
\begin{aligned}
& 20 \mathrm{~cm}: \mathrm{EV}=3,67(\Theta / 0,9055.0,2437)^{2,8742} \\
& 40 \mathrm{~cm}: \mathrm{EV}=3,67(\Theta / 0,9845.0,2818)^{6,2045} \\
& 60 \mathrm{~cm}: \mathrm{EV}=3,67(\Theta / 1,0.0,3258)^{4,3856} \\
& 80 \mathrm{~cm}: \mathrm{EV}=3,67(\Theta / 1,0.0,3795)^{2,5352} \\
& 100 \mathrm{~cm} \mathrm{EV}=3,67(\Theta / 1,0.0,3450)^{3,868}
\end{aligned}
$$

O valor de $\mathbf{k}$ nas equações (73) a (77), aumenta com a profundidade, evidenciando que a camada superficial governou o fluxo evaporativo, já que essa camada atinge a condição potencial para uma fração menor da umidade de saturação, em relação às camadas profundas; embora a evaporação possa ocorrer no interior do perfil, os baixos niveis de umidade na camada superficial reduzem a difusividade, tornando-se portanto, limitante. 


\subsection{Avaliação do modelo ajustado}

Tomando-se a umidade medida no primeiro dia do período (11/02), estimaram-se os armazenamentos subsequentes, a partir das funções de infiltração, percolação e evaporação ajustadas.

Os armazenamentos estimados e observados estão comparados na Figura 13.

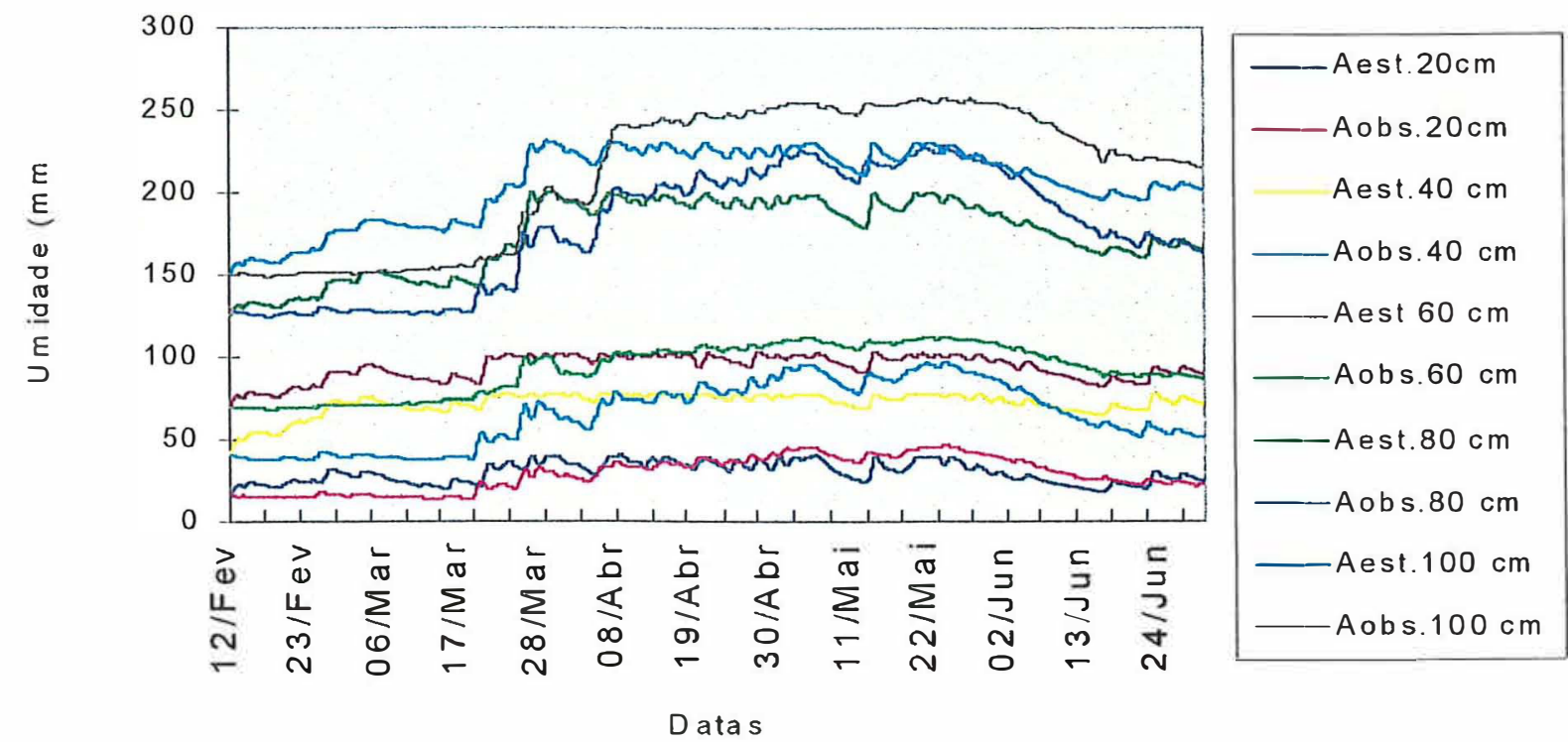

Figura 13. Armazenamentos estimado e observado no período de 11/02 a 30/06/95, Pentecoste-Ce.

Ao longo do experimento observou-se uma sequência de 3 sub-períodos coincidindo o primeiro com a fase inicial do trabalho até o início das chuvas; o segundo se prolongando por toda a estação chuvosa e o terceiro correspondendo com a fase de depleção da água no solo com o começo da escassez das 
precipitações; nos sub-períodos de baixa umidade (primeiro e terceiro), o armazenamento estimado superou o observado, enquanto na fase úmida ocorreu o contrário. Uma razão para esse fato, pode ser a subestimativa da evaporação pelo modelo na fase seca (nesta fase a percolação profunda é praticamente desprezível) e superestimativa da percolação profunda na fase úmida(nesta fase a evaporação sempre ocorreu próximo à condição de potencial).

Por outro lado, podem ter ocorrido problemas na determinação do armazenamento observado, principalmente no período seco, contribuindo para as diferenças observadas.

ROSE (1966) alerta para o fato de que em solos secos, a leitura da sonda de neutrons pode apresentar falhas devido à entrada e aprisionamento de ar nos poros. A análise estatística do desempenho do modelo, está sumarizada nos Quadros 6, 7 e 8.

Considerando o todo o período experimental, os menores desvios relativos observados foram para as profundidades de 60,80 e $100 \mathrm{~cm}$ e os maiores foram para 20 e $40 \mathrm{~cm}$; a maior variabilidade da camada superficial está de acordo com a característica dessa camada, no que diz respeito à maior velocidade de carga e recarga; 
Quadro 6 - Resumo dos parâmetros da avaliação estatística do MUSAG no período e 11/02 a 30/06/95.Pentecoste-Ce

\begin{tabular}{|c|c|c|c|c|c|c|c|c|c|}
\hline $\begin{array}{l}\text { Prof. } \\
(\mathrm{cm})\end{array}$ & $\begin{array}{l}A_{E S T} \\
\text { Méd }^{*}\end{array}$ & $\begin{array}{l}\text { AOBS } \\
\text { Méd* }\end{array}$ & $\begin{array}{l}D_{P A D} \\
(\mathrm{~mm})\end{array}$ & $D_{\text {REL }}$ & $\begin{array}{l}E_{P A D} \\
(\mathrm{~mm})\end{array}$ & $\begin{array}{l}\text { Coef. } \\
\text { Corre. }\end{array}$ & $\mathrm{C}_{\mathrm{s}}$ & $\mathrm{C}_{\mathrm{r}}$ & "t" \\
\hline 20 & 30,48 & 29,82 & 8,04 & 0,24 & 1,06 & 0,64 & 0,01 & $-1,21$ & 0,63 \\
\hline 40 & 72,43 & 65,59 & 16,95 & 0,26 & 1,77 & 0,58 & $-0,12$ & $-1,23$ & 3,86 \\
\hline 60 & 93,80 & 93,24 & 10,86 & 0,10 & 1,43 & 0,73 & $-0,51$ & $-0,98$ & 0,39 \\
\hline 80 & 173,87 & 177,98 & 18,73 & 0,09 & 3,62 & 0,90 & $-0,14$ & $-1,27$ & 1,14 \\
\hline 100 & 205,40 & 211,66 & 25,35 & 0,11 & 4,11 & 0,85 & $-0,44$ & $-1,39$ & 1,52 \\
\hline
\end{tabular}

$\left(^{*}\right)$ - $A_{E S T}$ - Armazenamento médio estimado; $A_{O B S}$ - Armazenamento médio; bservado; $D_{\text {PAD }}$ - Desvio padrão; $D_{R E L}$ - Desvio relativo; $E_{P A D}$ - Êrro padrão; Coef. Corre - Coeficiente de correlação; $\mathrm{C}_{s}$ - Coeficiente de assimetria; $\mathrm{C}_{R}$ - Coeficiente de curtose; $\mathrm{t}$ - Estatística " $\mathrm{t}$ " de Student

Quanto a $40 \mathrm{~cm}$, talvez seja devido a impropriedade do modelo para estimar umidade em profundidades coincidentes com a interface entre horizontes com diferenças de permeabilidade acentuada. Para as demais camadas os desvios relativos são de pequena magnitude assim como o êrro padrão.

Os coeficientes de correlação se mostraram significativos ao nível de $\alpha=0,01$ para todas as profundidades(SPENCE et alii,1968 - Tabela B), confirmando uma forte associação entre as duas amostras.

A Figura 14 mostra uma forte correlação entre as médias dos armazenamentos mensais estimados e dos armazenamentos mensais observados, uma vez que a dispersão dos pontos amostrados (25), distribui-se em torno da reta 1: 1 . 


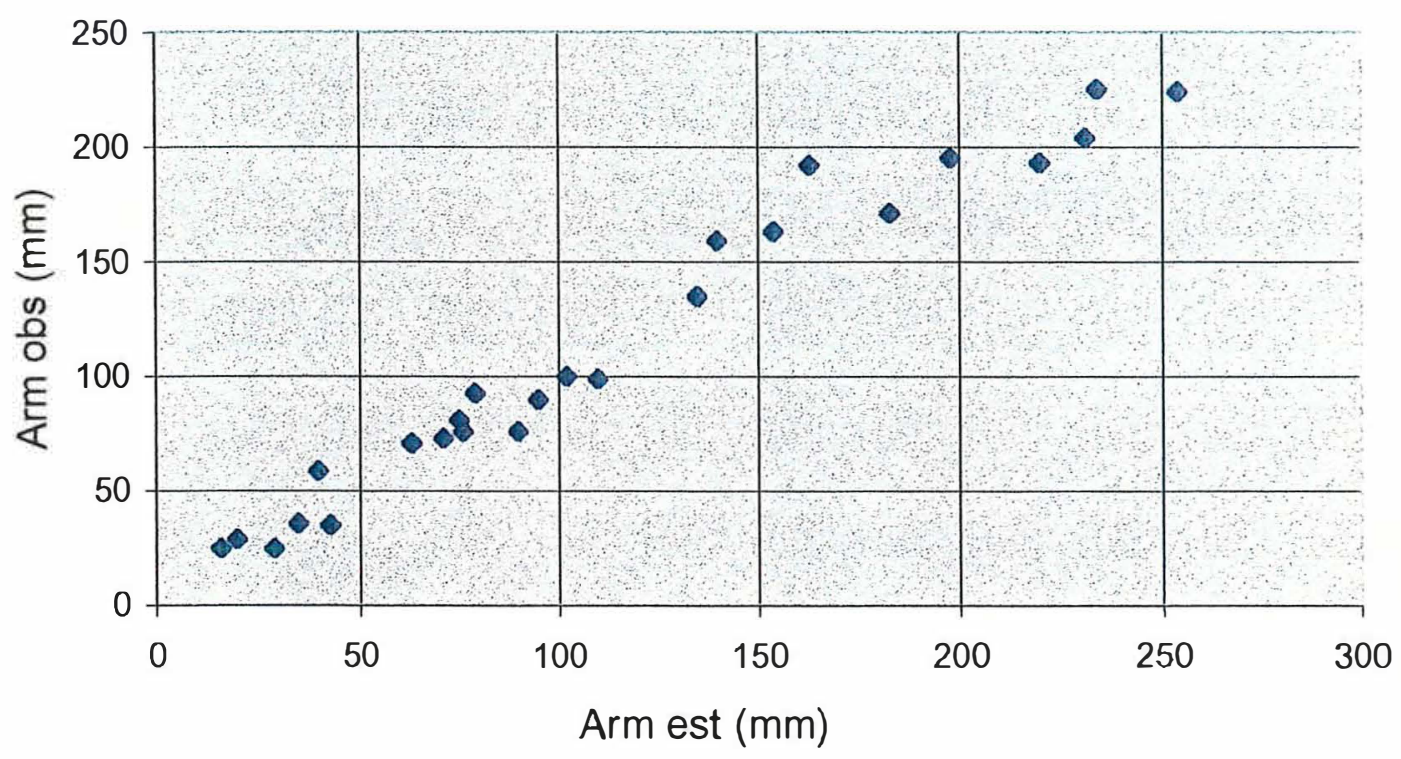

Figura 14 - Correlação entre as médias mensais dos armazenamentos estimado e observado (11/02 a 30/06/95), Pentecoste-Ce

Os coeficientes de assimetria tiveram valores próximos de zero, podendo-se assumir que os desvios observados entre os valores estimados e observados tem distribuição normal, embora a distribuição tenha um ramo assimétrico que se estende em direção aos valores mais negativos; os coeficientes de curtose para todas as profundidades tiveram valores em torno de $-1,0$ denotando uma distribuição relativamente plana, quanto à elevação do seu cume.

A hipótese testada é que $\mathbf{H}: \mu_{\mathrm{E}^{-}} \mu_{0}=0$, sendo $\mu_{\mathrm{E}}$ a média dos armazenamentos estimados e $\mu_{0}$ a média dos armazenamentos observados. O nível 
de significância adotado foi $\alpha=0,01$ e a estatística usada para testar a hipótese foi o teste " $t$ ". Assim, há $1 \%$ de chance de rejeitar-se a hipótese se ela for verdadeira.

Os valores de "t" calculados, à exceção de $40 \mathrm{~cm}$, não excedem o valor tabulado $(2,58)$ para o nível de significância adotado ; portanto, a hipótese $H: \mu_{E}-\mu_{0}$ $=0$ foi aceita, concluindo-se que o modelo calibrado com os parâmetros $I_{0}, I_{f}, \Theta_{0}$, ETP, $\alpha, \beta, \gamma$ e $\mathbf{k}$, pode ser utilizado para estimar a umidade um perfil para solo e clima semelhantes aos da área onde foi desenvolvida a pesquisa.

Os Quadros 7 e 8 mostram a análise estatística considerando-se um subperíodo seco (11/02 a 08/04) e um sub-período úmido (09/04 a 30/06).

De maneira semelhante quando foi considerado o período total, os menores desvios relativos observados, foram para as profundidades de 60,80 e $100 \mathrm{~cm}$.

Ao se considerar isoladamente o sub-período seco e o sub-período úmido, obviamente os valores dos armazenamentos estimados e observados, apresentam menor variabilidade em cada sub-período. como mostram os menores valores encontrados para os desvios padrão, relativo e êrro padrão. Embora essas distribuições não apresentem características de normalidade, os coeficientes de correlação calculados para distribuições não normais, se mostraram significativos ao nível de $\alpha=\mathbf{0 , 0 1}$, (exceto para 40 e $100 \mathrm{~cm}$ no período seco) quando comparados com os valores tabelados (SNEDECOR \& COCHRAN, 1956). 
Quadro 7 - Resumo dos parâmetros da avaliação estatística do MUSAG no período de $11 / 02$ a 08/04/95. Pentecoste-Ce

\begin{tabular}{lllllllll}
\hline $\begin{array}{l}\text { Camadas } \\
(\mathrm{cm})\end{array}$ & $\begin{array}{l}\mathrm{A}_{\mathrm{EST}} \\
\text { Méd }\end{array}$ & $\begin{array}{l}\text { Aobs } \\
\text { Méd }\end{array}$ & $\begin{array}{l}\mathrm{D}_{\mathrm{PAD}} \\
(\mathrm{mm})\end{array}$ & $\begin{array}{l}\mathrm{D}_{\mathrm{REL}} \\
0-20 \mathrm{~cm}\end{array}$ & $\begin{array}{l}\mathrm{E}_{\mathrm{PAD}} \\
(\mathrm{mm})\end{array}$ & $\begin{array}{l}\text { Coef. } \\
\text { Corre. }\end{array}$ & $\mathrm{C}_{\mathrm{S}}$ & $\mathrm{C}_{\mathrm{r}}$ \\
\hline $0-40 \mathrm{~cm}$ & 69,54 & 20,35 & 4.14 & 0.15 & 0.55 & 0.84 & -0.67 & 0.45 \\
$0-60 \mathrm{~cm}$ & 90,36 & 78,55 & 6,74 & 0,07 & 0,90 & 0,65 & $-0,11$ & $-0,83$ \\
$0-80 \mathrm{~cm}$ & 156,48 & 141,2 & 8,89 & 0,05 & 1,17 & 0,40 & 0,15 & $-0,18$ \\
$0-100 \mathrm{~cm}$ & 187,71 & 165,27 & 10,98 & 0,06 & 1,52 & $* * *$ & $-0,54$ & $-0,04$ \\
\hline
\end{tabular}

Quadro 8 - Resumo dos parâmetros da avaliação estatística do MUSAG no período de 09/04 a 30/06/95. Pentecoste-Ce

\begin{tabular}{|c|c|c|c|c|c|c|c|c|}
\hline $\begin{array}{l}\text { Camadas } \\
\text { (cm) }\end{array}$ & $\begin{array}{l}A_{E S T} \\
\text { Méd }\end{array}$ & $\begin{array}{l}\text { Aobs } \\
\text { Méd }\end{array}$ & $\begin{array}{l}D_{P A D} \\
(m m)\end{array}$ & $\overline{D_{\text {REL }}}$ & $\begin{array}{l}E_{P A D} \\
(m m)\end{array}$ & $\begin{array}{l}\text { Coef. } \\
\text { Corre. }\end{array}$ & $\mathrm{C}_{\mathrm{s}}$ & $\mathrm{C}_{\mathrm{r}}$ \\
\hline $0-20 \mathrm{~cm}$ & 31,57 & 36,22 & 5,36 & 0.13 & 0.58 & 0.96 & 0.33 & -0.72 \\
\hline $0-40 \mathrm{~cm}$ & 74,38 & 77,49 & 12,77 & 0,13 & 1,40 & 0,85 & 0,70 & 0,53 \\
\hline $0-60 \mathrm{~cm}$ & 96,12 & 103,16 & 4,81 & 0,04 & 0,53 & 0,94 & 0,69 & 0,21 \\
\hline $0-80 \mathrm{~cm}$ & 185,61 & 202,79 & 10,38 & 0,04 & 1,14 & 0,65 & 0,20 & $-1,08$ \\
\hline $0-100 \mathrm{~cm}$ & 217,33 & 242,96 & 7,43 & 0,02 & 0,82 & 0,38 & 0,14 & $-0,82$ \\
\hline
\end{tabular}




\section{CONCLUSÕES}

a) Para uma melhor desempenho do MUSAG e para manter a coerência com os postulados da teoria da infiltração da água no solo, o parâmetro CC (capacidade de campo) do modelo original, utilizado na estimativa da velocidade de infiltração, percolação e evaporação (equações 23,24 e 25 ) deve ser substituido por $\Theta_{\circ}$ (umidade de saturação).

b) Para o solo utilizado e nas condições experimentais, o modelo MUSAG, com calibração específica nessas condições, das funções e variáveis exigidas, permitiu valores estimados de armazenamento hídrico, estatisticamente não diferentes dos valores determinados por sonda de neutrons para todas as profundidades estudadas, com exceção da profundidade de $40 \mathrm{~cm}$.

c) Os parâmetros determinados devem ser adotados para as condições de solo e clima semelhantes aos da área estudada e após um processo de validação, utilizando dados de pelo menos três períodos secos e três períodos chuvosos;

d) Em solos semelhantes ao estudado, atenção especial deve ser dada ao monitoramento da água no solo na camada superficial, uma vez 
que para profundidades abaixo de $60 \mathrm{~cm}$, a variação da umidade se dá a uma taxa bastante pequena.

e) o modelo teve um desempenho menos satisfatório para estimar a umidade em profundidades onde ocorrem fortes variações texturais, próprias dos solos estratificados.

f) devido à variabilidade espacial das propriedades físicas dos solos, para uma mesma profundidade, e especialmente, para profundidades diferentes, a adoção do MUSAG para outros tipos de solos e de climas, requer uma parametrização e validação específica para cada situação perfeitamente delineada, do ponto de vista físico-hídrica. 


\section{REFERÊNCIAS BIBLIOGRÁFICAS}

AKAN, A. O. Horton Infiltration equation revisited. Journal of the Irrigation and Drainage Engineering. V.118, n.5, set/out. 1992.

ANDRADE, F. C. M. Modelo de umidade do solo para atividades agrícolas. FUNCEME. Fortaleza-CE,1995.

BASTIAANSSEN, W. G. M.; KABAT, P. \& MENENTI, M. A new simulation a model of bare soil evaporation in arid regions (EVADES).Institut Voor Cultuurtechnier en Waterhuishouding. Note 1938. Wageningen. Mai. 1989.

BLACK, T. A ; GARDNER, W. R. \& THURTELL, G. W. The prediction of evaporation, drainage in soils water storage for a bare soil. Soil Science Society American Proceedings. v.33, p. 655-660. 1969.

BOWER, H. Intake rate: Cilynder infiltrometer. In: Klute (Editor) Methods of soil analysis. Part 1. ASAE SSSA, Madison .Wisconsin. s. d.

CHANG, A. C.; SKAGGS, R. W.; HERMSMEIER, L. F.; \& JOHNSTON, W. R. Evaluation of a water management model for irrigated agriculture. Transactions of ASAE. v.3 p. 656-678. 1983. 
CLEMENTE, R. S.; DE JONG, R.; HAYHOE, H. N.; REYNOLDS, W. D. \& HARES, M. Testing and comparison of three insaturate soil water flow models. Agricultural Water Manegement v. 25 p. 132-152, 1994.

COLMAN, R. A . \& BODMAN, G.B. Moisture and energy conditions during downward entry of water into moist and layered soils.Soil Science Society Proceedings. V.9 p. 3-11. 1994.

CRANK, J. The mathematics of diffusion. Oxford Press, London, 1956.

DAVENPORT, D. C. Variations of evapotranspiration in time and space. I. Study of diurnal changes using evaporimeters and grass lysimeters. Journal of Hydrology. v.5 p. 312-328. 1967.

DOORENBOS, J. \& PRUITT, W. O . Guidelines for predicting crop water requirements. Food and Agriculture Organization. V. 24. 1977

EAGLEMAN J. R. \& JAMISON, V. C. Soil layering and compaction effects on insaturade moisture movement . Soil Science Society Proceedings. V. 519522. 1962.

EWING, L. K. \& MITCHELL, J. K. Parameter value prediction for Holtan"s infiltration equation. Transaction of ASAE. St.Joseph, v.29 n.1 1986.

FARIA, R. T.; MADRAMOOTOO, J.; BOISVERT, J. \& PRASHER, S. O . A comparison of the versatile soil moisture budget and swacrop models in Brazil. Paper. In: International Summer Meeting, North Caroline, 1992. The American Society of Agricultural Engineers, 21-24. 
FUNCEME. Estudo de solos de uma gleba da Fazenda Experimental da Universidade Federal do Ceará. Municipio de Pentecoste. Fortaleza. FUNCEME, 1995. 32p.

GARDNER, W. The cappilary potential and its relation to soil moisture contents. Soil Science. V.10 p. 257-259, 1920.

GREEN, W. H. \& AMPT, G. Studies of soil physics. Part I. The flow of air and water through soils. Journal of Agricultural Science V.4 p. 1-24, 1911.

GURALNK, D. Websters New Dictionary. Prentice Hall Press, New York.

HAAN, C. T. Parametric uncertainly in hydrologic moddelling. In:International Symposium of Moddelling Agricultural Forest and Rangelands Hydrology, Chicago, 1988. Proceedings. St.Joseph, Michigan, American Society of Agricultural Engineers,

HARTLEY, D. M. Interpretation of Kostiakov infiltration parameters for borders. Journal of Irrigation and Drainage Engineering. v.118 n.1, 1992.

HELAIA, A . M. The relation between soil infiltration and effective porosity in different soils. Agricultural Water Manegement, v.24, p. 39-47, 1993.

HOLTAN, H. N.; ENGLAND, C. B.; \& SHANHOLTZ. Concepts in hydrologic soil grouping. Transactions of ASAE, v.10, n.3, p. 407-410, 1967.

HORTON, R. E. An approach toward physical interpretation of infiltration capacity.

Soil Science Society American Proceedings. p. 399-417, 1940.

HUGGINS, L. F. \& MONKE, E. J. A mathematical model for simulating the hydrologic response of a watershed. Water Resource Research, v.4, p. 529-539, 1967. 
KOSTIAKOV, A. N. On the dynamics of the coefficient of water percolation in soils and on the necessity for studying it from a dynamic point of view for purposes of amelioration. In: Comm. Intern. Part A, 6th, Russian, 1932. Transactions. Russian Soil Science Society. 1932, p. 17-21.

LEITHOLD, L. O cálculo com geometria analítica. $2^{\text {a }}$.Ed. São Paulo: Editora HARBRA Ltda, 1986.

LIBARDI, P. L.; MANFRON, P. A .; MORAES, S. O .;\& TUON, R. L. Variabilidade da umidade gravimétrica de um solo hidromórfico. Revista Brasileira de Ciência do Solo. v. 20 p. 1-12. 1996.

LIBARDI, P. L.; REICHARDT. K.; NIELSEN, D. R. \& BIGGAR, J. W. Simplified field methods for estimating the insaturated hydraulic condictivity. Soil Science Society American. v.44 p. 3-7, 1980.

LIBARDI. P. L. Dinâmica da água no solo. Piracicaba. Paulo Leonel Libardi. 1995. 497p..

MALLANTS, D.; MOHANTY, B. P.; JAQUES, D. \& FEYEN, J. Spatial variability of hidraulic properties in a multi-layered soil profile Soil Science. V.161, n3, 1996.

MARCA. O . R. Evapotranspiração do consórcio milho-feijão-arroz. Fortaleza, 1985. Dissertação (Mestrado). Universidade Federal do Ceará.

MEIN, R. G. \& LARSON, C. L. Moddelling infiltration during a steady rain. Water Resource Research, v9, p. 384-394, 1973. 
MOLINAS, P. A . \& ANDRADE, F. C. M. Modelo de umidade do solo para atividades agrícolas. In: Simpósio Brasileiro de Recursos Hídricos, $X$ e Simpósio de Recursos Hídricos do Cone Sul I. Gramado, 1993. Anais. Gramado: 1993 v.VIII, p. 136-145.

MOREIRA, E. G. S. \& LIMA, F. A. M. Levantamento detalhado dos solos da Fazenda Experimental do Vale do Curu. Fortaleza: Universidade Federal do Ceará, 1973. 63p.

PAIGE, G. B. \& HILLEL, D. Comparison of three methods for assessing soil hydraulics properties. Soil Science. v.155, n.3, p. 175-189. 1993.

PEREIRA, A . R. Evapotranspiração. Piracicaba: Esalq/DFM, 1994.

PHILIP. J. R. The theory of infiltration. 4.Sorptivity and algebraic infiltration equations, Soil Science. v. 84, p. 257-264. 1957.

REICHARDT, K. Processos de transferência no sistema solo-planta-atmosfera. São Paulo: Fundação Kargil, 1985.

REICHARDT, K.; BACCHI, O . O . S.\& VILLAGRA, M. M. Estimativa de fluxo de água em solos não saturados. Bragantia, v.25, n1, p. 83-87. 1993.

RICHARDS, L. A . Capillary conduction of liquids through porous mediums. Physics, v.1, 1931.

ROSE, E. J. Agricultural Physics. Oxford: 1966. 230p.

SHARMA, M. L. Estimating evapotranspiration. Avances in Irrigation v.3, p. 213281. 1985. 
SILVA, Z. R. Climas do estado do Ceará. Ciência Agronômica. v.23 n. 1/2, p. 89 95. 1987.

SILVA, CC. \& DE JONG, R. Comparison of two computer models for predcting soil water in a tropical climate. Agricutlural. Forest Meteorology, v.36, p. 249-262, 1986.

SINGH, V.; PAL, D.; VARADE, S. B. \& KAR, S. Determining percolation losses of packed clay soil from tensiometer data. Agricultural Water Manegement, v.15 p.189-195, 1988.

SKAGGS, R. W. Field evaluation a water management simulation model. Transactions of ASAE, p. $\quad 666-674 \quad 1982$.

SKAGGS, R. W. \& KHAEEL, R. Infiltration. In: International Symposium of moddelling agricultural forest and rangelands hyrology, Chicago, 1988. St.Josph, Michigan: .American Society of Agricultural Engineers, 1988. p.1-9, 1988.

SKAGGS, R. W.; HUGGINS, L. E.; MONKE, E. J. \& FOSTER, G. R. Experimental evaluation of infiltration equations. Transactions of ASAE, v.12 n.6, p. $822-$ 828, 1969.

SNEDECOR, G. W. Statistical Methods: Applied to experiments in agriculture and biology. Fifth edition. lowa: The lowa State Colleg Press, 1956. 534p.

SMITH, R. E. \& HEBBERT, R. H. B. Mathematical simulation of interdependent surface and subsurface hydrologic processes. Water Resource Research. V.19, n.4, p.987-1001, 1983 
SPENCE, J. T.; COTTON, J. W.; UNDER WOOD, B. J.; \& DUNCAN, C. P..

Elementary Statistics. New Jersey: Prentice-Hall, New Jersey, 1968, 282p.

SUTIKTO, T. \& CHIKAMORI, K. Evaluation of Philip"s infiltration equation for cultivates upland terraces in Indonesia. Journal of Hydrology, Amsterdam, v.143, p. $279-295.1993$.

THORNTHWAITE, C. V. An approach toward a rational classification of climate. Geograph.Rev. v.38. p. 55-94 1948.

TURATTI, A . L. \& REICHARDT, K. Variabilidade do armazenamento da água em terra roxa estruturada. Revista Brasileira de Ciência do Solo, v.15, p. 253257. 1991.

VILLAGRA, M. M.; BACCHI, O . O . S.; TUON, R. L.; \& REICHARDT, K. Difficulties of estimating evapotranspiration from the water balance equation. Agricultural Forest Meteorology, v.72, p. 317-325, 1995.

WARTENA, L. Basic difficulties in predicting evaporation. Journal of Hydrology, Amsterdam, v.23. 1974.

ZAYANI, K.; BOUSNINA, H.; MHIRI, A .; HARTMANN, R. \& CHERIF, H. Evaporation in layered soils under differents rates of clay amendement. Agricultural Water Manegement, v.30 p. .143-154, 1996.

ZEPP, H. \& BELZ, A. Sensitivy and problems in moddelling soil moisture condtions. Journal of Hydrology, v. 131. P. 227-238, 1992. 